\title{
Cochrane
}

Library

Cochrane Database of Systematic Reviews

\section{Home versus in-patient treatment for deep vein thrombosis} (Review)

Othieno R, Okpo E, Forster R

Othieno R, Okpo E, Forster R.

Home versus in-patient treatment for deep vein thrombosis.

Cochrane Database of Systematic Reviews 2018, Issue 1. Art. No.: CD003076.

DOI: 10.1002/14651858.CD003076.pub3.

www.cochranelibrary.com 
TABLE OF CONTENTS

HEADER 1

ABSTRACT

PLAIN LANGUAGE SUMMARY

SUMMARY OF FINDINGS

BACKGROUND

OBJECTIVES

METHODS

RESULTS

Figure 1.

Figure 2.

Figure 3.

DISCUSSION

AUTHORS' CONCLUSIONS

ACKNOWLEDGEMENTS

REFERENCES

CHARACTERISTICS OF STUDIES

DATA AND ANALYSES

Analysis 1.1. Comparison 1 Treatment of DVT at home versus treatment in hospital, Outcome 1 Recurrence of VTE.

Analysis 1.2. Comparison 1 Treatment of DVT at home versus treatment in hospital, Outcome 2 Major bleeding.

Analysis 1.3. Comparison 1 Treatment of DVT at home versus treatment in hospital, Outcome 3 Minor bleeding.

Analysis 1.4. Comparison 1 Treatment of DVT at home versus treatment in hospital, Outcome 4 Death. 
[Intervention Review]

\section{Home versus in-patient treatment for deep vein thrombosis}

Richard Othieno ${ }^{1}$ Emmanuel Okpo², Rachel Forster ${ }^{3}$

1NHS Lothian, Directorate of Public Health and Health Policy, Edinburgh, UK. 2Public Health Directorate, NHS Grampian, Aberdeen, UK.

3Usher Institute of Population Health Sciences and Informatics, University of Edinburgh, Edinburgh, UK

Contact address: Richard Othieno, NHS Lothian, Directorate of Public Health and Health Policy, Waverly Gate, 2-4 Waterloo Place, Edinburgh, EH13EG, UK. richard.othieno@nhslothian.scot.nhs.uk.

Editorial group: Cochrane Vascular Group.

Publication status and date: New search for studies and content updated (no change to conclusions), published in Issue 1, 2018.

Citation: Othieno R, Okpo E, Forster R. Home versus in-patient treatment for deep vein thrombosis. Cochrane Database of Systematic Reviews 2018, Issue 1. Art. No.: CD003076. DOI: 10.1002/14651858.CD003076.pub3.

Copyright @ 2018 The Cochrane Collaboration. Published by John Wiley \& Sons, Ltd.

\section{A B S T R A C T}

\section{Background}

Deep vein thrombosis (DVT) occurs when a blood clot blocks blood flow through a vein, which can occur after surgery, after trauma, or when a person has been immobile for a long time. Clots can dislodge and block blood flow to the lungs (pulmonary embolism (PE)), causing death. DVT and PE are known by the term venous thromboembolism (VTE). Heparin (in the form of unfractionated heparin (UFH)) is a bloodthinning drug used during the first three to five days of DVT treatment. Low molecular weight heparins (LMWHs) allow people with DVT to receive their initial treatment at home instead of in hospital. This is an update of a review first published in 2001 and updated in 2007.

\section{Objectives}

To compare the incidence and complications of venous thromboembolism (VTE) in patients treated at home versus patients treated with standard in-patient hospital regimens. Secondary objectives included assessment of patient satisfaction and cost-effectiveness of treatment.

\section{Search methods}

For this update, the Cochrane Vascular Information Specialist searched the Cochrane Vascular Specialised Register (last searched 16 March 2017), the Cochrane Central Register of Controlled Trials (CENTRAL; 2017, Issue 2), and trials registries. We also checked the reference lists of relevant publications.

\section{Selection criteria}

Randomised controlled trials (RCTs) examining home versus hospital treatment for DVT, in which DVT was clinically confirmed and was treated with LMWHs or UFH.

\section{Data collection and analysis}

One review author selected material for inclusion, and another reviewed the selection of trials. Two review authors independently extracted data and assessed included studies for risk of bias. Primary outcomes included combined VTE events (PE and recurrent DVT), gangrene, heparin complications, and death. Secondary outcomes were patient satisfaction and cost implications. We performed metaanalysis using fixed-effect models with risk ratios (RRs) and 95\% confidence intervals (Cls) for dichotomous data.

\section{Main results}

We included in this review seven RCTs involving 1839 randomised participants with comparable treatment arms. All seven had fundamental problems including high exclusion rates, partial hospital treatment of many in the home treatment arms, and comparison of UFH in hospital versus LMWH at home. These trials showed that patients treated at home with LMWH were less likely to have recurrence of VTE events than those given hospital treatment with UFH or LMWH (fixed-effect risk ratio (RR) $0.58,95 \%$ confidence interval (CI) 0.39 to $0.86 ; 6$ studies; 1708

Home versus in-patient treatment for deep vein thrombosis (Review) 
participants; $\mathrm{P}=0.007$; low-quality evidence). No clear difference was seen between groups for major bleeding ( $\mathrm{RR} 0.67,95 \% \mathrm{Cl} 0.33$ to 1.36; 6 studies; 1708 participants; $P=0.27$; low-quality evidence), minor bleeding (RR $1.29,95 \% \mathrm{Cl} 0.94$ to $1.78 ; 6$ studies; 1708 participants; $\mathrm{P}=0.11$; low-quality evidence), or mortality (RR $0.69,95 \% \mathrm{Cl} 0.44$ to $1.09 ; 6$ studies; 1708 participants; $\mathrm{P}=0.11$; low-quality evidence). The included studies reported no cases of venous gangrene. We could not combine patient satisfaction and quality of life outcomes in metaanalysis owing to heterogeneity of reporting, but two of three studies found evidence that home treatment led to greater improvement in quality of life compared with in-patient treatment at some point during follow-up, and the third study reported that a large number of participants chose to switch from in-patient care to home-based care for social and personal reasons, suggesting it is the patient's preferred option (very low-quality evidence). None of the studies included in this review carried out a full cost-effectiveness analysis. However, a small randomised economic evaluation of the two alternative treatment settings involving 131 participants found that direct costs were higher for those in the in-patient group. These findings were supported by three other studies that reported on their costs (very low-quality evidence).

Quality of evidence for data from meta-analyses was low to very low. This was due to risk of bias, as many of the included studies used unclear randomisation techniques, and blinding was a concern for many. Also, indirectness was a concern, as most studies included a large number of participants randomised to the home (LMWH) treatment group who were treated in hospital for some or all of the treatment period. A further issue for some outcomes was heterogeneity that was evident in measurement and reporting of outcomes.

\section{Authors' conclusions}

Low-quality evidence suggests that patients treated at home with LMWH are less likely to have recurrence of VTE than those treated in hospital. However, data show no clear differences in major or minor bleeding, nor in mortality (low-quality evidence), indicating that home treatment is no worse than in-patient treatment for these outcomes. Because most healthcare systems are moving towards more LMWH usage in the home setting it is unlikely that additional large trials will be undertaken to compare these treatments. Therefore, home treatment is likely to become the norm, and further research will be directed towards resolving practical issues by devising local guidelines that include clinical prediction rules, developing biomarkers and imaging that can be used to tailor therapy to disease severity, and providing training for community healthcare workers who administer treatment and monitor treatment progress.

\section{PLAIN LANGUAGE SUMMARY}

\section{Home versus in-patient treatment for deep vein blood clots}

\section{Background}

Deep vein thrombosis (DVT) occurs when a blood clot blocks the flow of blood through a vein, generally in the legs. This can happen after surgery, after trauma, when a person is immobile for a long time, or for no obvious reason. Clots can dislodge and block blood flow to the lungs (pulmonary embolism (PE)), which can be fatal. DVT and PE are known as venous thromboembolism (VTE). Heparin is a bloodthinning drug that is used to treat DVT during the first three to five days. Unfractionated heparin (UFH) is administered intravenously in hospital with laboratory monitoring. Low molecular weight heparins (LMWHs) are given by subcutaneous injection once a day and can be given at home. Oral anticoagulants are then continued for three to six months. After recovery from the acute episode, people may develop post-thrombotic syndrome with leg swelling, varicose veins, and ulceration.

\section{Study characteristics and key results}

Seven randomised controlled trials involving 1839 patients with clinically confirmed DVT compared home (LMWH) versus hospital (unfractionated heparin, or LMWH in one trial) treatment. Trials had limitations, including high exclusion rates and designs that did not take into account short hospital stays for any of the people treated at home to allow fair comparison of heparin in hospital with LMWH at home.

Trials showed that patients treated at home with LMWH had less recurrence of VTE than hospital-treated patients. The review showed no clear differences between treatment groups for major bleeding, minor bleeding, or death. No study reported venous gangrene. We could not pool information on patient satisfaction and quality of life, as studies had different ways of reporting these, but two of the three studies reporting on quality of life provided evidence that home treatment led to greater improvement in quality of life compared with in-patient treatment, at some point during follow-up. The third study reported that a large number of participants chose to switch from in-patient care to home-based care for social and personal reasons, indicating that home treatment was better accepted than in-patient treatment. Studies that looked at cost found that cost of home management was lower per incident of treatment.

\section{Quality of the evidence}

Overall, the quality of evidence of the available data was low to very low owing to risk of bias, indirectness, and differences in measuring and reporting of outcomes. Risk of bias is a concern, as many of the included studies did not fully explain how they randomised and allocated participants to treatments, and blinding techniques described were not clear. Full blinding would be difficult if not impossible for these types of treatments (home vs hospital), but some techniques could be put in place such as using the same treatment medications or blinding those who measure outcomes. Another concern of reviewers was that in some studies, participants randomised to home treatment actually ended up being treated in hospital but remained in their assigned treatment for the analysis (this is known as indirectness). This makes it hard to determine whether trial results actually can be used to answer the question of whether home versus 
hospital treatment for DVT is superior. A further concern regarding a few of outcomes is variation in the way outcomes were measured and reported. 
SUMMARY OF FINDINGS

Summary of findings for the main comparison. Treatment of DVT at home compared with treatment in hospital

How does treatment of DVT at home compare with treatment in hospital?

Patient or population: people with diagnosed DVT

Setting: hospital and home

Intervention: treatment of DVT at home with $\mathrm{LMWH}^{a}$

Comparison: treatment of DVT in hospital with UFH or LMWHb

\begin{tabular}{|c|c|c|c|c|c|c|}
\hline \multirow[t]{2}{*}{ Outcomes } & \multirow{2}{*}{$\begin{array}{l}\text { No. of partici- } \\
\text { pants } \\
\text { (studies) } \\
\text { Follow-up }\end{array}$} & \multirow{2}{*}{$\begin{array}{l}\text { Quality of the } \\
\text { evidence } \\
\text { (GRADE) }\end{array}$} & \multirow[t]{2}{*}{$\begin{array}{l}\text { Relative effect } \\
(95 \% \mathrm{Cl})\end{array}$} & \multicolumn{2}{|c|}{$\begin{array}{l}\text { Anticipated absolute effects }{ }^{\star}(95 \% \\
\mathrm{Cl})\end{array}$} & \multirow[t]{2}{*}{ Comments } \\
\hline & & & & $\begin{array}{l}\text { Risk with } \\
\text { treatment of } \\
\text { DVT in hospital }\end{array}$ & $\begin{array}{l}\text { Risk difference } \\
\text { with treatment } \\
\text { of DVT at home }\end{array}$ & \\
\hline \multirow{2}{*}{$\begin{array}{l}\text { Recurrence of VTE } \\
\text { Follow-up: range } 3 \\
\text { months to } 12 \text { months }\end{array}$} & \multirow{2}{*}{$\begin{array}{l}1708 \\
(6 \mathrm{RCTs})\end{array}$} & \multirow{2}{*}{$\begin{array}{l}\oplus \oplus \ominus \ominus \\
\text { LOWc,d }\end{array}$} & \multirow{2}{*}{$\begin{array}{l}\text { RR } 0.58 \\
\text { (0.39 to } 0.86)\end{array}$} & \multicolumn{2}{|l|}{ Study population } & \\
\hline & & & & 74 per 1000 & $\begin{array}{l}31 \text { fewer per } 1000 \\
\text { ( } 45 \text { fewer to } 10 \\
\text { fewer) }\end{array}$ & \\
\hline Venous gangrene & See comment. & & & & & $\begin{array}{l}\text { This outcome was not reported by any of the } \\
\text { included studies. }\end{array}$ \\
\hline \multirow{2}{*}{$\begin{array}{l}\text { Major bleeding } \\
\text { Follow-up: range } 14 \\
\text { days to } 12 \text { months }\end{array}$} & \multirow{2}{*}{$\begin{array}{l}1708 \\
\text { (6 RCTs) }\end{array}$} & \multirow{2}{*}{$\begin{array}{l}\oplus \oplus \ominus \ominus \\
\text { LOWc,d }\end{array}$} & \multirow{2}{*}{$\begin{array}{l}\text { RR } 0.67 \\
\text { (0.33 to } 1.36)\end{array}$} & \multicolumn{2}{|l|}{ Study population } & \\
\hline & & & & 21 per 1000 & $\begin{array}{l}7 \text { fewer per } 1000 \\
\text { (14 fewer to } 8 \\
\text { more) }\end{array}$ & \\
\hline \multirow{2}{*}{$\begin{array}{l}\text { Minor bleeding } \\
\text { Follow-up: range } 14 \\
\text { days to } 12 \text { months }\end{array}$} & \multirow{2}{*}{$\begin{array}{l}1708 \\
\text { (6 RCTs) }\end{array}$} & \multirow{2}{*}{$\begin{array}{l}\oplus \oplus \ominus \ominus \\
\text { LOWc,d }\end{array}$} & \multirow{2}{*}{$\begin{array}{l}\text { RR } 1.29 \\
\text { (0.94 to } 1.78)\end{array}$} & \multicolumn{2}{|l|}{ Study population } & \\
\hline & & & & 72 per 1000 & $\begin{array}{l}21 \text { more per } 1000 \\
\text { ( } 4 \text { fewer to } 56 \\
\text { more) }\end{array}$ & \\
\hline \multirow{2}{*}{$\begin{array}{l}\text { Death } \\
\text { fFollow-up: range } 3 \\
\text { months to } 12 \text { months }\end{array}$} & \multirow{2}{*}{$\begin{array}{l}1708 \\
\text { (6 RCTs) }\end{array}$} & \multirow{2}{*}{$\begin{array}{l}\oplus \oplus \ominus \ominus \\
\mathrm{LOWc}, \mathrm{d}\end{array}$} & \multirow{2}{*}{$\begin{array}{l}\text { RR } 0.69 \\
\text { (0.44 to } 1.09)\end{array}$} & \multicolumn{2}{|l|}{ Study population } & \\
\hline & & & & 49 per 1000 & 15 fewer per 1000 & \\
\hline
\end{tabular}




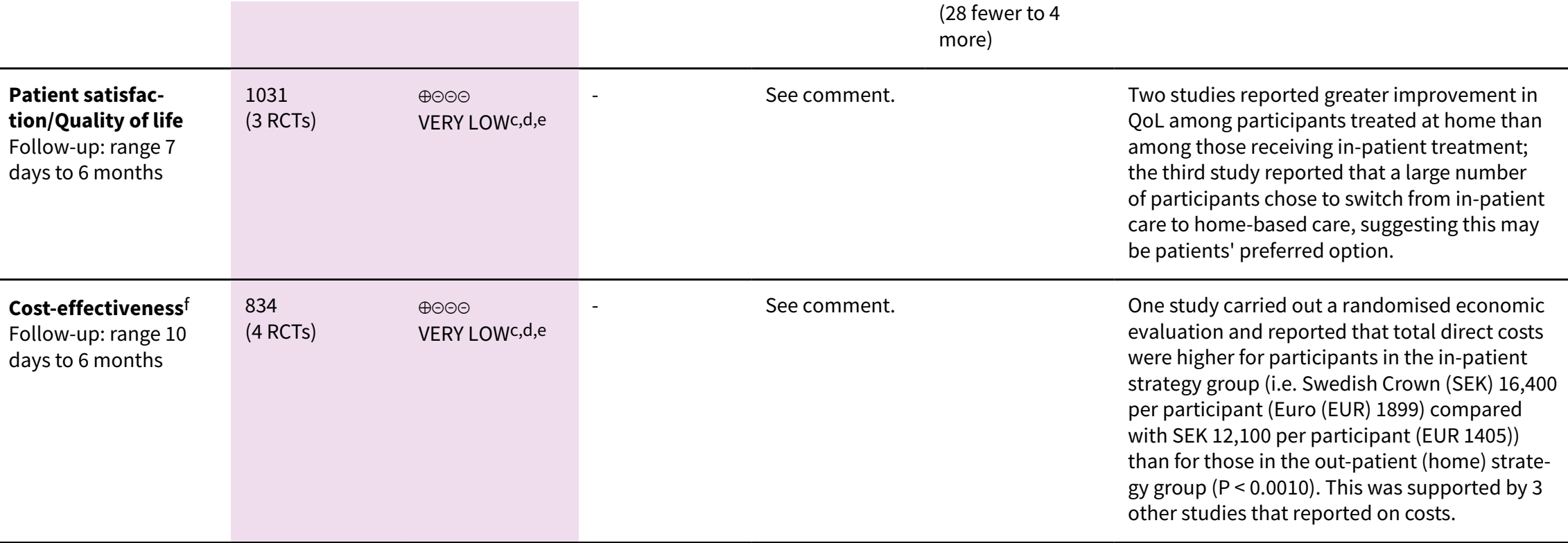

*We calculated the assumed risk of the hospital treatment group from the average risk in the hospital treatment group (i.e. the number of participants with events divided by the total number of participants in the hospital treatment group included in the meta-analysis). The risk in the intervention group (and its $95 \%$ confidence interval) is based on the assumed risk in the comparison group and the relative effect of the intervention (and its $95 \% \mathrm{Cl}$ ).

Cl: confidence interval; DVT: deep vein thrombosis; LMWH: low molecular weight heparin; RR: risk ratio; UFH: unfractionated heparin; VTE: venous thromboembolism.

\section{GRADE Working Group grades of evidence.}

High quality: We are very confident that the true effect lies close to that of the estimate of the effect.

Moderate quality: We are moderately confident in the effect estimate: The true effect is likely to be close to the estimate of the effect, but there is a possibility that it is substantially different.

Low quality: Our confidence in the effect estimate is limited: The true effect may be substantially different from the estimate of the effect.

Very low quality: We have very little confidence in the effect estimate: The true effect is likely to be substantially different from the estimate of effect.

a Home treatment refers to treatment for DVT with an LMWH that occurs outside of a hospital or in-patient setting and can include the medication being administered by the participant or by a caregiver.

bHospital treatment refers to treatment for DVT with an LMWH or a UFH in a hospital or in-patient setting that is administered by care staff.

cDowngraded one level owing to risk of bias from unclear randomisation techniques and blinding measures in most included studies.

dDowngraded one level owing to indirectness because most of the included studies had few participants actually treated at home with an LMWH, and many were treated in hospital.

eDowngraded one level owing to heterogeneity because the included studies used different methods and time points for gathering information on this outcome.

fWe are reporting on the cost-effectiveness analysis reported in the included studies. We have not carried out an economic analysis ourselves. 


\section{B A C K G R O U N D}

\section{Description of the condition}

Deep vein thrombosis (DVT) is a frequent disorder in western medical practice, affecting one to two per thousand of the adult population annually. DVT occurs in conjunction with malignancy, after surgery, and after trauma and immobilisation, and can occur spontaneously. It manifests in the acute stage with leg symptoms and, in a small minority, with potentially fatal pulmonary embolism (PE). Venous thromboembolism (VTE) is a term that refers to both DVT and PE. After recovery from the acute episode, people may develop post-thrombotic syndrome with leg swelling, varicosis, and ulceration. Gold standard techniques for diagnosing DVT include ascending venography and duplex ultrasound scanning. Deep vein thrombosis is most commonly managed by anticoagulants to prevent spread of the clot proximally and to allow it to become adherent or undergo fibrinolysis, thus reducing the risk of PE. Currently used anticoagulant treatments include unfractionated and low molecular weight heparin (UFH and LMWH, respectively), as well as vitamin $\mathrm{K}$ antagonists (VKAs), primarily warfarin, and direct oral anticoagulants (DOACs) (NICE 2012; Robertson 2015; van Es 2014).

\section{Description of the intervention}

In the hospitalised patient, UFH is usually administered intravenously, with laboratory monitoring for about five days, overlapping with oral anticoagulants, which are continued for three to six months. LMWH is administered daily by subcutaneous injection; it can be delivered at home without the need for continuous laboratory monitoring and may be followed by an oral anticoagulant regimen.

\section{Why it is important to do this review}

Development of LMWHs has resulted in many trials investigating their efficaciousness and safety, as compared with UFH. These studies show that LMWH is at least as effective as UFH; some meta-analyses and reviews show that LMWH is more effective and safer than UFH (Erkens 2010; Leizorovicz 1994; Lensing 1995). Because LMWH is given subcutaneously once per day and requires no laboratory monitoring, it is possible to treat people with LMWH at home. Although LMWH has been available since 1976, home treatment has not been investigated further since the time it was first reported in 1988 (Bakker 1988). Rigorous evaluation of home versus in-patient care is required to inform policy on alternative strategies for treating patients with DVT. Home treatment of DVT offers potential cost savings and improved social acceptability for the patients. This review aims to update the review that was first published in 2001 and updated in 2007 (Othieno 2007).

\section{OB JECTIVES}

To compare the incidence and complications of venous thromboembolism (VTE) in patients treated at home versus patients treated with standard in-patient hospital regimens. Secondary objectives included assessment of patient satisfaction and cost-effectiveness of treatment.

\section{METHODS}

\section{Criteria for considering studies for this review}

Types of studies

We included randomised controlled trials (RCTs) in which participants were randomised to home or in-patient treatment. Exclusion criteria before randomisation had to be stated and the trial author's policy regarding protocol violations and withdrawals known (i.e. intention-to-treat basis).

\section{Types of participants}

We included people with proven VTE who had no contraindication to heparin therapy, and whose home circumstances were adequate. Participants had to present with objective evidence of DVT such as duplex scanning and/or venography.

\section{Types of interventions}

We included studies that compared home versus hospital management with LMWH (which can be used in either setting) or UFH (which is used in hospital only). Trials involving a placebo group are not ethically acceptable.

\section{Types of outcome measures}

\section{Primary outcomes}

- Recurrence of VTE: PE or recurrence of DVT (depending on length of follow-up)

- Venous gangrene

- Heparin complications: major and minor bleeding (the former defined as bleeding within the abdomen, cranium, or eye, or requiring transfusion, or causing a fall in haemoglobin $\geq 2 \mathrm{~g} / \mathrm{dL}$ )

- Death

Ideally, evidence of PE is derived from lung scans, spiral computed tomography (CT), or pulmonary angiography, but as these methods were not likely to be widely available, we considered X-rays, electrocardiograms (ECGs), and strong clinical signs acceptable. In the event of death, postmortem evidence was desirable.

\section{Secondary outcomes}

- Patient satisfaction and quality of life

- Cost-effectiveness of treatment (as reported by individual studies)

We will also report on other outcomes of interest (i.e. postthrombotic syndrome or length of stay in hospital), when reported by individual studies.

\section{Search methods for identification of studies}

\section{Electronic searches}

For this update, the Cochrane Vascular Information Specialist (CIS) searched the following databases for relevant trials.

- Cochrane Vascular Specialised Register (16 March 2017).

- Cochrane Central Register of Controlled Trials (CENTRAL; 2017, Issue 2) via the Cochrane Register of Studies Online.

See Appendix 1 for details of the search strategy used for CENTRAL. 
The Cochrane Vascular Specialised Register is maintained by the CIS and is constructed from weekly electronic searches of MEDLINE Ovid, Embase Ovid, the Cumulative Index to Nursing and Allied Health Literature (CINAHL), and the Allied and Complementary Medicine Database (AMED), as well as through handsearching of relevant journals. The full list of databases, journals, and conference proceedings searched, as well as the search strategies used, are described in the Specialised Register section of the Cochrane Vascular module in the Cochrane Library (www.cochranelibrary.com).

In addition, the CIS searched the following trial databases for details of ongoing and unpublished studies (16 March 2017). See Appendix 2.

- World Health Organization (WHO) International Clinical Trials Registry Platform (ICTRP) Search Portal (apps.who.int/ trialsearch).

- ClinicalTrials.gov (clinicaltrials.gov).

- International Standard Randomised Controlled Trial Number (ISRCTN) Registry (www.isrctn.com).

\section{Searching other resources}

We identified additional articles by reviewing the references of relevant papers identified by the initial search.

\section{Data collection and analysis}

\section{Selection of studies}

For this update, three review authors (RO, EO, RF) independently selected trials. Final selection of articles was agreed upon through discussion and consensus.

\section{Data extraction and management}

Two review authors (RO, EO) independently extracted data from existing and newly included trials using the criteria designated by Cochrane Vascular. For some references, we sought clarification from trial authors. Two review authors (RO, EO) performed data entry.

\section{Assessment of risk of bias in included studies}

Two review authors (RO, EO) independently assessed the risk of bias of all included studies using Cochrane's 'Risk of bias' tool, as described in the Cochrane Handbook for Systematic Reviews of Interventions (Higgins 2011). We rated studies as having 'low risk of bias' (plausible bias that is unlikely to seriously alter the results); 'high risk of bias' (plausible bias that seriously weakens confidence in the results); or 'unclear risk of bias' (plausible bias that raises some doubt about results). We assessed included RCTs against the six domains listed below.

- Sequence generation: Was the allocation sequence adequately described?

- Allocation concealment: Was allocation adequately concealed?

- Blinding of participants, personnel, and outcome assessors: Was knowledge of the allocation intervention adequately prevented during the study?

- Incomplete outcome data: Were incomplete outcome data adequately addressed?
- Selective outcome reporting: Are reports of the study free of the suggestion of selective outcome reporting?

- Other sources of bias: Did the study appear to be free of other problems that could put it at high risk of bias?

\section{Measures of treatment effect}

Two review authors (RO, EO) performed the data analysis according to the statistical guidelines provided for review authors by Cochrane Vascular. When data were sufficient, we calculated risk ratios (RRs) with 95\% confidence intervals (Cls) using Review Manager software (RevMan 2014).

\section{Unit of analysis issues}

None of the included studies applied non-standard designs, such as cross-over trials or cluster-randomised trials. Therefore we made no adjustments for measurement effects. The individual participant was the unit of analysis.

\section{Dealing with missing data}

We aimed to conduct a complete-case analysis in this Cochrane Review, such that we included in the analysis all participants with a recorded outcome. We analysed data on an intention-totreat basis as far as possible. When data were missing, we made attempts to obtain them from the original investigators. When they were unobtainable, we analysed only available data, based on the numerator and the denominator reported in study results or calculable from reported percentages.

\section{Assessment of heterogeneity}

We examined heterogeneity between trials by visually examining forest plots to judge whether any differences between studies in direction or size of the treatment effect were apparent. We also considered $\mathrm{I}^{2}$ and $\mathrm{Tau}^{2}$ statistics and the $\mathrm{P}$ value of the $\mathrm{Chi}^{2}$ test for heterogeneity. If we identified heterogeneity among trials (i.e. if the value of $\mathrm{I}^{2}$ was greater than $30 \%$, and the value of $\mathrm{Tau}^{2}$ was greater than zero or the $\mathrm{P}$ value of the $\mathrm{Chi}^{2}$ test for heterogeneity was lower than 0.1 ), we planned to explore heterogeneity by performing prespecified sensitivity analysis as described below.

\section{Assessment of reporting biases}

In view of the difficulty involved in detecting and correcting for publication bias and other reporting biases, we aimed to minimise their potential impact by ensuring a comprehensive search for eligible studies and by staying alert for duplication of data. We planned to use a funnel plot to assess the possibility of small-study effects (a tendency for estimates of the intervention effect to be more beneficial in smaller studies) for the primary review outcomes when we included 10 or more studies in meta-analyses (Higgins 2011). We intended to cautiously consider visible asymmetry in the funnel plot as a possible indication of publication bias.

\section{Data synthesis}

We carried out statistical analysis using Review Manager software (RevMan 2014). We used a fixed-effect meta-analysis for combining data when it was reasonable to assume that studies were estimating the same underlying treatment effect (i.e. when trials were examining the same intervention, and when we judged that trial populations and methods were sufficiently similar). 
We planned to use random-effects meta-analysis if clinical heterogeneity was sufficient to expect that underlying treatment effects differed between trials, or if we detected substantial statistical heterogeneity.

\section{Subgroup analysis and investigation of heterogeneity}

If identified, we planned to explore any possible evidence of heterogeneity within meta-analyses by performing subgroup analysis. We planned to perform no other subgroup analyses.

\section{Sensitivity analysis}

We performed sensitivity analyses by excluding studies that we judged to be at high risk of bias to determine effects on overall findings. We also performed sensitivity analysis if a single study carried most of the weight when we included three or more studies in an analysis. We performed additional sensitivity analysis to determine the robustness of findings that included data from Koopman 1996, Levine 1996, and Ramacciotti 2004, when we found that participants randomised to LMWH were treated only at home, as determined by a clinician, but were not specifically assigned to home treatment.

\section{'Summary of findings'}

We presented the main findings of the review concerning quality of evidence, magnitude of effect of interventions examined, and the sum of available data for all outcomes of this review (Types of outcome measures) in a 'Summary of findings' table, according to GRADE principles, as described by Higgins 2011 and Atkins 2004. We evaluated evidence on the basis of risk of bias of the included studies, inconsistency, indirectness, and imprecision of data, as well as publication bias. We used GRADEprofiler (GRADEpro) software to assist in preparation of the 'Summary of findings' table (GRADEProGDT 2015), and we used the Ryan 2016 publication to prepare GRADE ratings.

\section{RES U L T S}

\section{Description of studies}

\section{Results of the search}

See Figure 1. 
Figure 1. Study flow diagram.

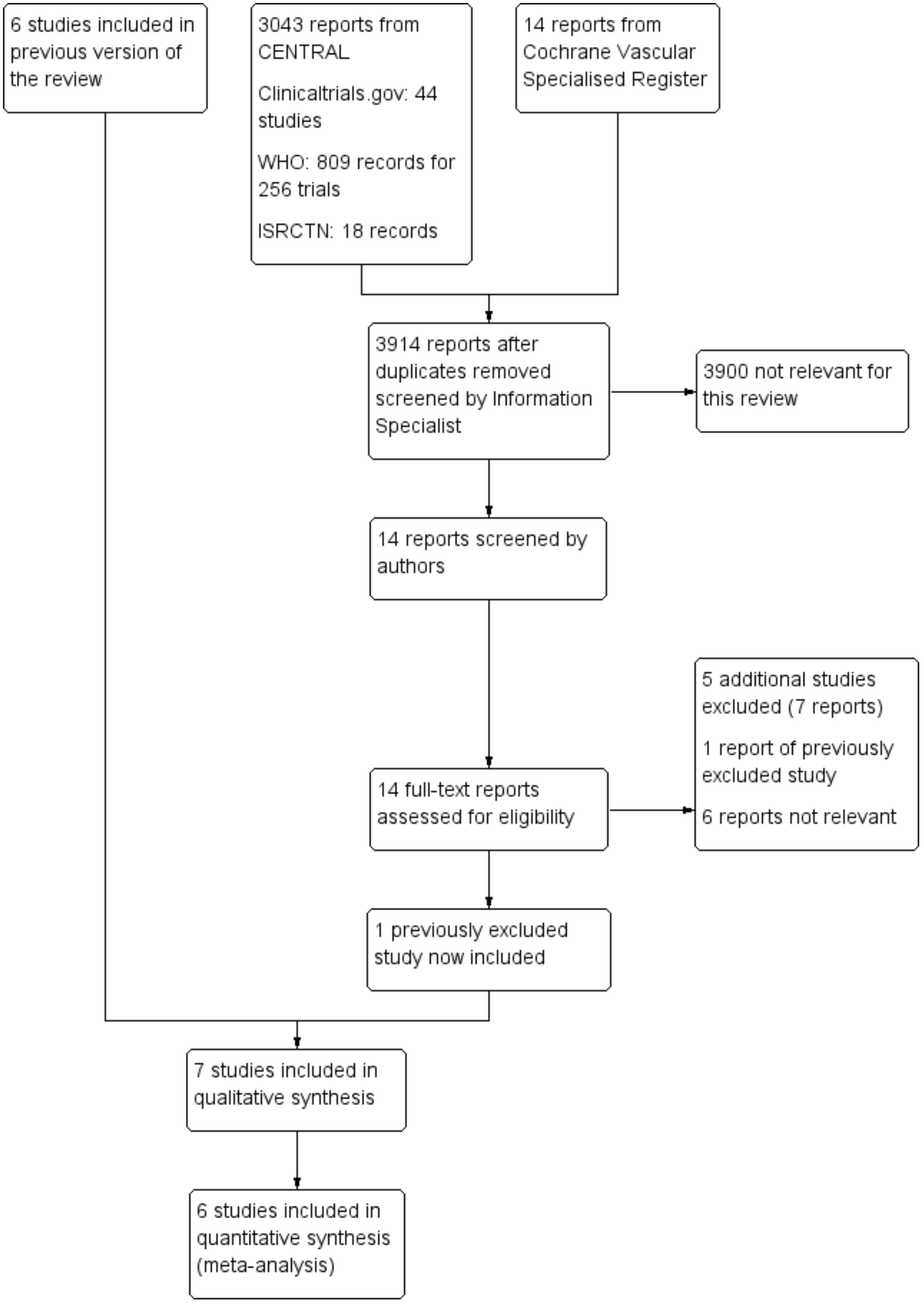




\section{Included studies}

In total, seven studies with a total of 1839 participants were eligible for inclusion in this review (Bäckman 2004; Boccalon 2000; Chong 2005; Daskalopoulos 2005; Koopman 1996; Levine 1996; Ramacciotti 2004). We identified one new study for inclusion in this review update (Bäckman 2004). This study had previously been excluded on the grounds that it did not assess any of the primary outcomes, but after further assessment, we decided we should include it, as the study did report on economic data.

Three large trials randomised 298 (150 home and 148 hospital), 400 (202 home and 198 hospital), and 500 participants ( 247 home and 253 hospital), respectively (Chong 2005; Koopman 1996; Levine 1996). Three trials were smaller (Boccalon 2000; Daskalopoulos 2005; Ramacciotti 2004). Boccalon 2000 reported results on 201 randomised participants (99 home and 102 hospital); Ramacciotti 2004 reported results on 104 home and 97 hospital randomised participants; and in Daskalopoulos 2005, investigators randomised 108 participants (55 to home and 53 to hospital). Bäckman 2004 evaluated and compared direct and indirect medical costs during a three-month period for 131 randomised participants (65 outpatient/home and 66 in-patient).

Bäckman 2004 did not report on any of the predefined outcomes of this review other than costs; therefore we did not include this study in any meta-analyses for these outcomes.

The three major trials (Chong 2005; Koopman 1996; Levine 1996) were similar in construction and results but differed in their exclusion rates (see Characteristics of included studies; further discussed in Overall completeness and applicability of evidence). Of the seven trials, only Boccalon 2000 and Bäckman 2004 used LMWH in both treatment arms; the other five used LMWH in home treatment arms and UFH in hospital treatment arms.

See Characteristics of included studies tables for further details of the included studies.

\section{Excluded studies}

For this update, we excluded an additional five studies (Aujesky 2011; Hull 2009; Modesto-Alapont 2006; Otero 2010; Wilson 2003), for a total of 26 excluded studies (Aujesky 2011; Belcaro 1999; Blattler 1998; Buller 2004; Conner 1999; Fitzmaurice 2000; Frank 1998; Goldhaber 1998; Grau 1998; Grau 2001; Green 1998; Hull
2000; Hull 2002; Hull 2009; Lindmarker 1996; Miles 1998; ModestoAlapont 2006; O'Shaugnessy 1998; Otero 2010; Pineo 2003; Rymes 2002; Ting 1998; Wells 1998; White 1989; Wilson 2003; Wimperis 1998).

Eight were uncontrolled studies (Conner 1999; Grau 1998; Green 1998; Lindmarker 1996; Miles 1998; O'Shaugnessy 1998; Ting 1998; Wimperis 1998), and two were retrospective studies (Grau 2001; Rymes 2002). We excluded the remaining 16 trials for a variety of reasons. We excluded two reported controlled trials because participants were not actually randomised but instead were treated according to their expressed therapeutic preferences (Blattler 1998; Frank 1998). We excluded Wells 1998 because this study compared patient-administered versus nurse-administered injections rather than the location of treatment; Goldhaber 1998 because participants randomised to treatment with LMWH in a home setting were first required to be treated in hospital for several days; Otero 2010 and Aujesky 2011 because these studies focussed on PE - not DVT; Belcaro 1999 because this was primarily a trial of formulations of heparin rather than a trial of home versus hospital treatment; Hull 2000 and Modesto-Alapont 2006 because investigators were concerned with prophylactic regimens including LMWH for patients undergoing hip arthroplasty and for those with VTE in obstructive pulmonary disease, respectively; Pineo 2003 and Hull 2002 because they investigated two protocols on long-term effects of LMWH treatment - not location; and two other trials because they did not include in-patient arms Wilson 2003 compared anticoagulant clinics versus family clinics, and Hull 2009 compared long-term subcutaneous tinzaparin versus initial tinzaparin followed by long-term warfarin in the community as opposed to home patients versus in-patients. White 1989 and Fitzmaurice 2000 were concerned with monitoring oral anticoagulation at home or in general practitioner (GP) surgery. Buller 2004 compared once-daily LMWH versus twice-daily doses in the out-patient setting, and LMWH versus UFH in the out-patient setting - not hospital versus home.

See also Characteristics of excluded studies.

\section{Risk of bias in included studies}

Figure 2 gives an overall view of our assessment of included studies' risk of bias, and Figure 3 shows the 'Risk of bias' summary presented as percentages across all included studies. See also Characteristics of included studies. 
Figure 2. 'Risk of bias' summary: review authors' judgements about each risk of bias item for each included study.

\begin{tabular}{|c|c|c|c|c|c|c|c|}
\hline & 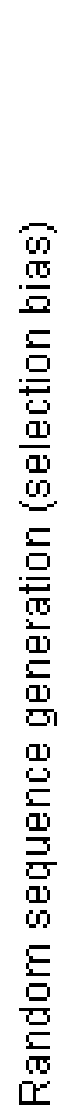 & 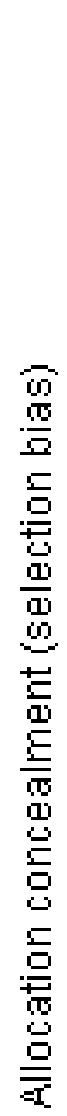 & 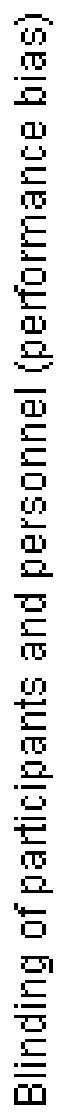 & 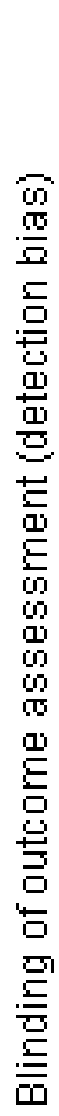 & 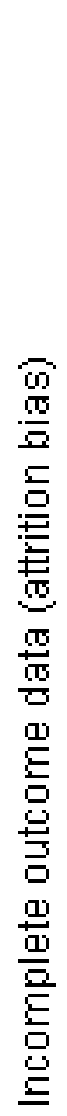 & 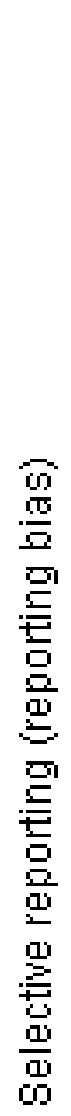 & 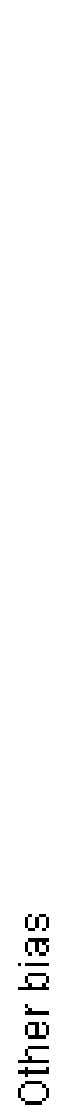 \\
\hline Bäckman 2004 & $?$ & & & & & & $?$ \\
\hline Boccalon 2000 & $?$ & & & & & & + \\
\hline Chong 2005 & $?$ & $?$ & & & & & $?$ \\
\hline Daskalopoulos 2005 & + & $?$ & & & & & + \\
\hline Koopman 1996 & $?$ & + & & & & & $?$ \\
\hline Levine 1996 & $?$ & + & & & & & $?$ \\
\hline Ramacciotti 2004 & $?$ & & & & & & $?$ \\
\hline
\end{tabular}


Figure 3. 'Risk of bias' graph: review authors' judgements about each risk of bias item presented as percentages across all included studies.

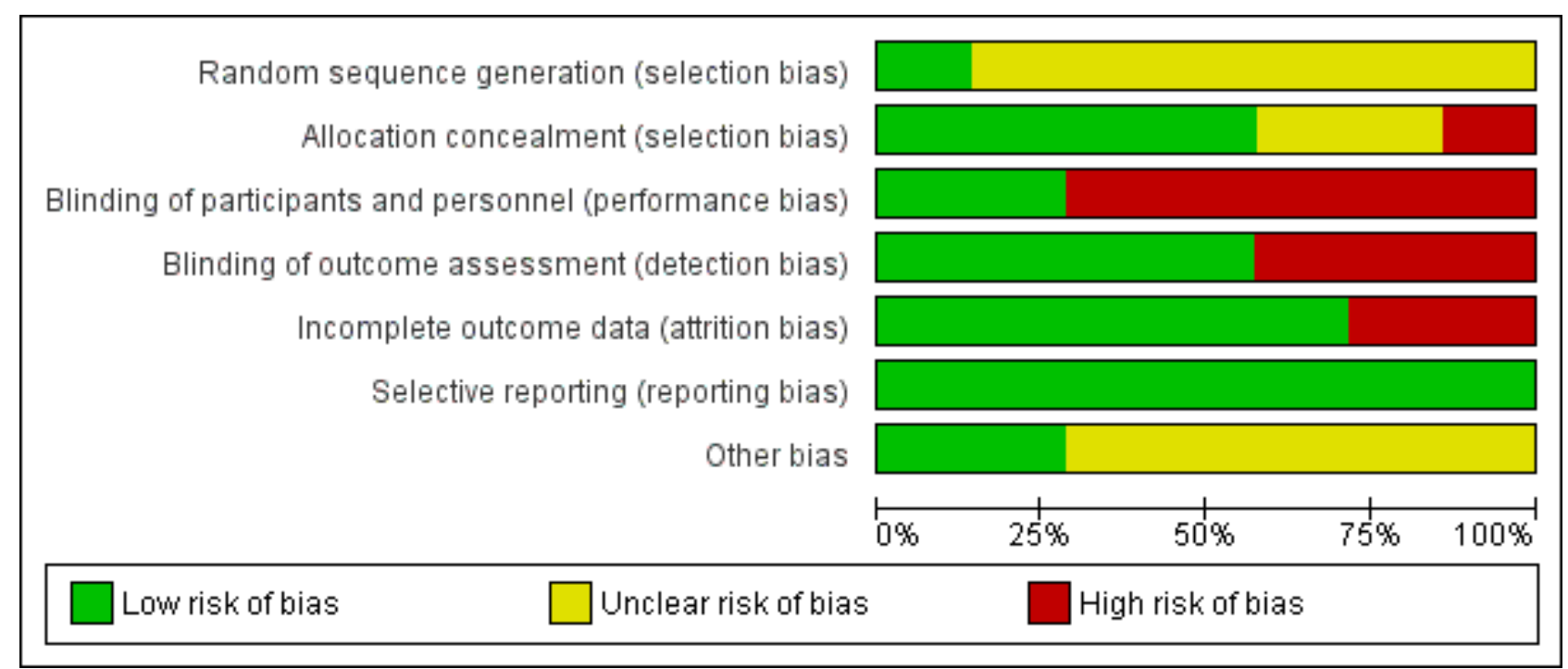

\section{Allocation}

We considered the following methods of allocation concealment adequate.

- Central allocation, including telephone randomisation.

- Use of sequentially numbered, opaque, sealed envelopes.

We deemed risk of bias as low if study authors described one of these methods. We deemed risk of bias as unclear if researchers described the trial as randomised but did not describe the method used for allocation concealment.

All included trials were reported as randomised controlled trials (RCTs). Random sequence generation was unclear in six studies (Bäckman 2004; Boccalon 2000; Chong 2005; Koopman 1996; Levine 1996; Ramacciotti 2004) but was adequate in a single trial (Daskalopoulos 2005) as these investigators reported using a computerised process.

Four trials adequately concealed allocation (Bäckman 2004; Boccalon 2000; Koopman 1996; Levine 1996). Daskalopoulos 2005 did not report the method used, and Chong 2005 did not report allocation concealment, so we rated both as having unclear risk of bias. In the Ramacciotti 2004 study, researchers performed randomisation by using blocks in an 'open manner'; we rated this study as having high risk of bias.

\section{Blinding}

Blinding refers to whether participants and study personnel knew which participants were treated in hospital, and which received treatment at home. By the nature of this study, blinding was never going to be easy to achieve. Five studies were open, non-blinded studies (Chong 2005; Daskalopoulos 2005; Koopman 1996; Levine 1996; Ramacciotti 2004); we judged them to be at high risk of bias. Participants in Bäckman 2004 were allowed to change their assigned treatment or to leave the study after randomisation, but we determined the risk of performance bias as low for the outcomes of this study. Although Boccalon 2000 reported no blinding of participants or personnel, both groups received the same treatment. All participants received an oral anticoagulant for the first three days. The review authors deemed that outcomes were unlikely to have been affected by lack of blinding of participants or personnel, and so we judged this trial to be at low risk of bias.

Four studies had independent outcome assessors, and we deemed them to have low risk of detection bias (Chong 2005; Daskalopoulos 2005; Koopman 1996; Levine 1996). Three studies did not report blinding of outcome assessors; therefore we deemed these studies to be at high risk of detection bias (Bäckman 2004; Boccalon 2000; Ramacciotti 2004).

\section{Incomplete outcome data}

Five of the seven included studies either reported on all participants or adequately described their loss to follow-up; we rated them as low risk (Bäckman 2004; Chong 2005; Daskalopoulos 2005; Koopman 1996; Levine 1996). Ramacciotti 2004 and Boccalon 2000 had a high rate of attrition, and we rated them as high risk.

\section{Selective reporting}

We assessed a study for risk of selective outcome reporting according to the following.

- The published report included all expected outcomes.

- Outcomes were reported systematically for all comparison groups, based on prospectively collected data.

We deemed risk of bias to be low if both of these criteria were met, unclear if these criteria were not met, and high if evidence indicated that data had been collected on outcomes of interest but were not reported in the study publication.

We did not find any indication suggesting that outcomes were selectively reported in the included studies, so we rated all studies as low risk. 


\section{Other potential sources of bias}

We had no concerns regarding other potential sources of bias for two studies (Boccalon 2000; Daskalopoulos 2005). For Bäckman 2004, Chong 2005, Koopman 1996, Levine 1996, and Ramacciotti 2004, information was insufficient for review authors to judge whether there was potential for other bias; we rated these as having unclear risk, as each study included a large number of participants in the LMWH/home treatment group who were treated in hospital. Koopman 1996, Levine 1996, and Ramacciotti 2004 differed methodologically, as participants randomised to LMWH were treated only at home, as determined by a clinician, but were not specifically assigned to home treatment. We evaluated these studies by performing sensitivity analysis to assess their impact on evidence obtained through meta-analysis. We have discussed these issues further in the section Overall completeness and applicability of evidence.

\section{Effects of interventions}

See: Summary of findings for the main comparison Treatment of DVT at home compared with treatment in hospital

We have presented a summary of the findings of this review in Summary of findings for the main comparison, and a summary of outcomes of included trials in Table 1.

\section{Recurrent VTE (PE or recurrence of DVT)}

Six studies reported on this outcome (Boccalon 2000; Chong 2005; Daskalopoulos 2005; Koopman 1996; Levine 1996; Ramacciotti 2004). Outcome follow-up time ranged from three months to one year. Pooled results showed differences in recurrence of VTE between home and hospital treatment, with home treatment carrying less risk of recurrent VTE (RR $0.58,95 \% \mathrm{Cl} 0.39$ to $0.86 ; 1708$ participants; 6 studies; $I^{2}=0 \% ; \mathrm{P}=0.007$; Analysis 1.1 ). We rated the evidence as low quality owing to risk of bias and indirectness concerns.

\section{Venous gangrene}

Included studies reported no cases of venous gangrene.

\section{Heparin complications including major and minor bleeding}

Six studies reported on this outcome (Boccalon 2000; Chong 2005; Daskalopoulos 2005; Koopman 1996; Levine 1996; Ramacciotti 2004). Outcome follow-up ranged from 14 days to one year.

Pooling of results on major bleeding revealed no clear differences between home and hospital treatment groups (RR 0.67, 95\% Cl 0.33 to $1.36 ; 1708$ participants; 6 studies; $I^{2}=0 \% ; P=0.27$; Analysis 1.2). We rated the evidence as low quality owing to risk of bias and indirectness concerns.

For the outcome of minor bleeding, data show no clear differences between hospital and home treatment arms (RR 1.29, 95\% Cl 0.94 to $1.78 ; 1708$ participants; 6 studies; $I^{2}=0 \% ; P=0.11$; Analysis 1.3 ). We rated the evidence as low quality owing to risk of bias and indirectness concerns.

\section{Death}

Six studies included reports on death, with follow-up ranging from three months to one year (Boccalon 2000; Chong 2005; Daskalopoulos 2005; Koopman 1996; Levine 1996; Ramacciotti
2004). Meta-analysis of trial results showed no clear differences in numbers of deaths between home- and hospital-treated groups (RR $0.69,95 \% \mathrm{Cl} 0.44$ to $1.09 ; 1708$ participants; 6 studies; $I^{2}=0 \% ; P=$ 0.11 ; Analysis 1.4). We rated the evidence as low quality owing to risk of bias and indirectness concerns.

\section{Patient satisfaction and quality of life}

Three studies included data on quality of life (QoL) (Bäckman 2004; Koopman 1996; Levine 1996). Bäckman 2004 assessed QoL using the EuroQoL tool based on five dimensions (EQ-5D) and found no differences between treatment groups in mean QoL scores, nor in the proportion of participants showing improvement in selfrated health state. QoL was assessed immediately after treatment and after three months. A substantial number of participants randomised to in-patient care in this study chose out-patient treatment, predominantly as a personal/social preference. The Koopman 1996 trial measured QoL by using the Medical Outcome Study Short Form 20 as a generic measure of physical and mental health, as well as an adapted version of the Rotterdam Symptom Checklist, which is specific to thrombosis; measurements were taken at baseline, at end of treatment course, and at 12 weeks and 24 weeks after treatment. At 24 weeks after treatment, over $80 \%$ of both trial groups had completed the QoL questionnaires. Overall, participants in both groups showed improvement in QoL; two out of six criteria (physical activity and social functioning) showed an advantage for those in the LMWH group at completion of initial treatment, but this difference was not seen at 12 weeks or at 24 weeks after treatment. Levine 1996 reported on QoL seven days after treatment using the Medical Outcomes Study Short Form 36 , which reports on eight physical and mental health domains. Only the social functioning domain showed greater improvement among participants treated at home compared with those given heparin treatment; data show no differences between the two treatment groups in terms of the other domains (O'Brien 1999). We could not carry out meta-analysis for this outcome owing to heterogeneity in reporting of QoL and the paucity of data reported by trial authors.

We rated the quality of evidence for this outcome as very low owing to risk of bias, indirectness, and heterogeneity of measurement and reporting.

\section{Cost-effectiveness of treatment}

Bäckman 2004, Boccalon 2000, Daskalopoulos 2005, and Koopman 1996 all reported on cost-effectiveness of compared treatments, but because of the way investigators presented data, we could perform no meta-analysis for this outcome.

In Bäckman 2004, which reported on costs within three months of treatment, 224 participants were eligible, 131 entered the trial, and 124 completed the economic portion of the study. Total direct costs were higher for participants in the in-patient strategy group(i.e. Swedish Crown (SEK) 16,400 per participant (Euro (EUR) 1899) compared with SEK 12,100 per participant (EUR 1405)) than for those in the out-patient (home) strategy group $(\mathrm{P}<0.0010)$.

Koopman 1996 followed participants for six months and used trial results to compare cost of treatment calculations between the two arms of the trial (van den Belt 1998). Data show a 64\% savings among those treated with LMWH as opposed to UFH, largely owing to lower hospital costs. Trialists stated that this was a conservative estimate of the potential reduction in costs. Similarly, an evaluation 
of participants entered into the Levine 1996 trial showed cost savings of 57\% (O'Brien 1999); researchers followed participants for three months. This latter figure is confirmed by Boccalon 2000 , which showed that the mean cost of in-patient treatment over 10 days was over $55 \%$ higher than the mean cost of out-patient treatment over the same time period. Similarly, in Daskalopoulos 2005, which reported on 12 months of follow-up, estimated costs slightly favoured the LMWH group because of the significant cut in hospitalisation.

We rated the quality of evidence for this outcome as very low owing to risk of bias, indirectness, and heterogeneity of measurement and reporting.

\section{Other outcomes of interest}

None of the included trials considered the incidence of postthrombotic syndrome.

Mean hospital stay for participants without events such as bleeding or (suspected) recurrences in Koopman 1996 was 8.1 days for the hospital-treated 'control' group, and 2.7 days for the home-treated 'treatment' group. In the other large trial (Levine 1996), mean hospital stay was 6.5 days for the hospital-treated control group and 2.1 days for the home-treated group. Mean hospital stay in Boccalon 2000 was 9.6 days for the hospital-treated group and one day for the home-treated group. Ramacciotti 2004 reported a mean hospital stay of three days for home-treated participants and seven days for hospital-treated participants. Three studies did not report duration of hospital stay (Bäckman 2004; Chong 2005; Daskalopoulos 2005).

Thirty-six per cent of participants in Koopman 1996 were treated entirely at home, 39\% had a short hospital stay, and 25\% were entirely hospital treated. Fifty per cent of participants in Levine 1996 were treated entirely at home. In Daskalopoulos 2005, no participant allocated to receive treatment with LMWH underwent any hospitalisation.

Seventy-seven per cent of participants in the home arm (LMWH group) of the Chong 2005 trial were admitted to hospital. Twelve per cent were released on the day of admission, 34\% were kept for one day, and 31\% were kept for two or more nights. Ramacciotti 2004 reported hospitalisation for all hospital-treated participants and for $64 \%$ of home-treated participants.

\section{Heterogeneity, subgroup analysis, and sensitivity analysis}

We found heterogeneity in pooled effect estimates to be very low and had no reason to further investigate. When we performed sensitivity analysis, we found no difference in the effect when we removed studies at high risk of bias (Ramacciotti 2004). No analyses showed a majority weight by a single study, so we performed no sensitivity analyses on these criteria. We performed sensitivity analysis by evaluating the impact of the Koopman 1996, Levine 1996, and Ramacciotti 2004 trials given that participants randomised to LMWH were treated only at home, as determined by a clinician, but were not specifically assigned to home treatment. This sensitivity analysis did not change the findings.

\section{DISCUSSION}

\section{Summary of main results}

This review presents low-quality evidence suggesting that patients treated at home with low molecular weight heparin (LMWH) are less likely to have recurrence of venous thromboembolism (VTE) than those treated in an in-patient (hospital) setting. Data show no clear differences in major or minor bleeding events nor in mortality (all low-quality evidence), indicating that home treatment is no worse for these outcomes when compared with in-patient treatment.

\section{Overall completeness and applicability of evidence}

Although the results of this review are promising, review authors have several concerns about the applicability of the evidence. Our primary concern is that a large number of participants in the home treatment group were not treated solely at home. Also, there was heterogeneity in the findings of the larger trials, making it difficult to interpret and apply the results. Finally, a large number of eligible participants were excluded from trials before randomisation, raising concerns about applicability.

Many of the participants randomised to home treatment with LMWH were not actually treated fully at home but were hospitalised for some or all of the treatment period (see Table 2 for details). Only $40 \%$ (in Bäckman 2004), 23\% (in Chong 2005), 36\% (in Koopman 1996), $48.5 \%$ (in Levine 1996), and 36\% (in Ramacciotti 2004) of those randomised to home treatment were treated wholly at home, making trial results difficult to interpret. In three trials, participants randomised to LMWH treatment, as opposed to unfractionated heparin (UFH), could be treated at home or in an in-patient setting at the discretion of clinicians or investigators (Koopman 1996; Levine 1996; Ramacciotti 2004). This creates the concern that data collected and reported in meta-analyses may not directly speak to the question at hand. To address these issues, we conducted extensive sensitivity analyses and found no differences in our findings when we excluded the findings of these studies. This issue is a problem not just with these few trials; rather, it is an overall, possibly insurmountable problem, as deep vein thrombosis (DVT) and its complications by their nature may require in-patient treatment, even if a person is deemed acceptable for home treatment. However, these trials have shown that patients treated at home with LMWH are less likely to have recurrence of VTE than their counterparts treated in hospital with UFH or LMWH. Also, researchers found that participants preferred to have treatment at home. Concerns presented here most likely contribute to dilution of review conclusions.

The three major randomised controlled trials (RCTs) compared UFH in hospital versus LMWH at home (Chong 2005; Koopman 1996; Levine 1996). A more methodologically sound trial would have compared LMWH in both groups, and this would have been justified by the many trials and three meta-analyses showing that LMWH is at least as effective as UFH (Erkens 2010; Leizorovicz 1994; Lensing 1995).

Another factor limiting review conclusions was the very high prerandomisation exclusion rate reported by several trials (Boccalon 2000; Koopman 1996; Levine 1996). Koopman 1996 reported exclusion of $31 \%$ of eligible participants, and Levine 1996 reported exclusion of $67 \%$. Similarly, Boccalon 2000 (78\%) and Bäckman 2004 (42\%) reported high exclusion rates. Exclusion 
criteria were very diffuse and could have been less strict. Daskalopoulos 2005 presented a contrasting low exclusion rate (7\%). Ramacciotti 2004 and Chong 2005 did not report on prerandomisation exclusions, except for three participants in the Chong 2005 trial, who were enrolled but were not randomised because they did not receive study treatment or did not provide treatment-related data.

Although we have included 'economic analysis' as an outcome, a comprehensive economic analysis is beyond the scope/expertise of this review, so we have reported only limited data available from the included studies.

Other issues that may affect applicability of our review include the limited number of participants from developing countries, and the fact that no high-quality RCTs have been published since 2005 .

Trends in the treatment of individuals with VTE have been changing recently, with practitioners moving away from UFH and using more LMWHs along with the newer class of direct oral anticoagulants (DOACs). Treatment with LMWHs and DOACs has been shown to be efficacious, with no increase in clinically relevant complications (Robertson 2015; Robertson 2017). Although UFH treatment is not going to disappear completely, practitioners have been moving away from its usage and embracing LMWH and DOACs owing to monitoring requirements and subsequent costs of treatment with UFH. However, clinicians using DOACs to treat patients with VTE have to reckon with their complexity, involving appropriate dose selection for the relevant indication, avoidance of drug-drug and drug-disease interactions, and consideration of dose adjustments in specific clinical situations, such as organ dysfunction (Finks 2016). This review did not evaluate any studies that included the use of DOACs, such as rivaroxaban or dabigatran, as no such studies met our inclusion criteria. We therefore have presented limited evidence in this review for detailed discussion of their use.

\section{Quality of the evidence}

Strengths of the evidence include the consistency and homogeneity of results from individual studies, as well as sufficient numbers of participants and events included for each outcome. However, we downgraded evidence generated in this review to low quality owing to concerns about risk of bias of individually included studies, as well as indirectness of the data due to issues surrounding hospitalisation of participants randomised to home treatment, as discussed in the previous section. A major concern associated with risk of bias was selection bias: All seven included studies were at unclear or high risk for concerns with random sequence generation or allocation concealment. Although minimising performance bias would be very difficult owing to the open nature of the treatment, making blinding of participants and personnel nearly impossible, these issues could be addressed in other ways, such as keeping treatment drugs consistent between interventions or demonstrating more stringent control of detection bias. Risk of bias concerns led us to downgrade the quality of evidence by one level. These concerns reduce the robustness of findings. See Summary of findings for the main comparison for further information.

We conducted sensitivity analysis by evaluating the strength of evidence in light of risk of bias issues, as well as concerns with indirectness, and we found that findings did not change when we removed studies with high risk of bias, or studies that may not have directly contributed to the objectives of the review.
We did not investigate publication bias for the review because we included fewer than 10 studies in the individual meta-analyses, precluding robust results in the funnel plots used to investigate publication bias.

\section{Potential biases in the review process}

During the review process, we adhered to all possible measures to reduce potential biases, including conducting a comprehensive search, performing double data extraction, and grading the evidence. We made attempts to identify relevant studies and discussed disagreements thoroughly.

\section{Agreements and disagreements with other studies or reviews}

The results of uncontrolled trials encompass a considerable body of evidence (Table 3), particularly in relation to practical questions (see Implications for research). An observational study that included 334 participants concluded that community-based treatment of individuals with thromboembolism was safe and effective (Hyers 2007). Home treatment has also been investigated in specific pathological communities, including individuals with cancer, and was found to be a suitable alternative to in-patient care (Ageno 2005).

In the UK, some local health authorities (Trusts) have published the results of uncontrolled studies. Swindon Trust reported that 373 patients were referred to the programme, of whom $32 \%$ had proven DVT and $37.5 \%$ were treated wholly or partially at home (Green 1998). Chertsey Trust reported on 1093 referrals, of which 160 were proven to have a diagnosis of DVT. All but one (i.e. 159 patients) were home-treated (O'Shaugnessy 1998). Researchers have reported no complications apart from two minor bleeds and estimated savings to Chertsey Trust as $£ 320,000$ over 22 months. In a combined presentation to the American Thoracic Society, three trusts reported that they managed the care of 966 patients with DVT, of whom only $10 \%$ were admitted to hospital (Miles 1998). In Norwich, 447 patients were referred over a six-month period, scans were positive in $30 \%$, and $20 \%$ of these were considered unsuitable for home treatment (Wimperis 1998). Thus, 105 were treated and five had to be readmitted - two with suspected pulmonary embolism (PE) (negative scans), one with PE, one with stroke, and one with an unrelated illness (Wimperis 1998).

A study from Melbourne presented 100 participants with proven DVT (Ting 1998). Fifty-three participants had proximal thrombosis and were admitted for one day for investigation, including lung scan: 16 scans were positive, although participants were asymptomatic and the result did not affect their management at home. The 47 participants with distal thrombosis were treated entirely at home. The clot was initially extended in $13.2 \%$ of distal and $2.7 \%$ of proximal thromboses, but at follow-up scans at six months, $60.7 \%$ of distal and $18.5 \%$ of proximal thromboses had completely resolved. The only complications were six minor bleeds. The numbers of participants referred but cleared of DVT, and the numbers rejected by the protocol, were not mentioned. In a Swedish study, 434 participants with DVT were treated in hospital for three days before discharge home on treatment (Lindmarker 1996). Three participants had proven PE: One major bleed and 16 minor ones occurred. Data show no deaths in the acute stage and no extension of thromboses. In Grau 1998, 39 out of 71 participants with DVT were treated at home. Investigators reported no instance 
of PE and only one minor bleed. These trials all reported worthwhile cost savings. Only one uncontrolled study reported on patient satisfaction (Conner 1999). Seventy-nine per cent of participants were happy to be treated at home, $12 \%$ would have preferred hospital treatment, and $9 \%$ had no preference.

Although not based on evidence from RCTs, cost savings in favour of home treatment have been shown when calculated. Hospital Episode Statistics for the UK for 1993 show 17,000 admissions for PE and 25,000 for DVT, with an average in-patient stay of 7.2 days (Griffin 1996). At an estimated cost of $£ 200$ per in-patient day (1998 figures), hospitalisation costs alone amounted to $£ 60,480,000$. If this could be reduced to, say, two days in $75 \%$ of cases, at a cost of $£ 12,600,000$, a savings of $£ 47,880,000$ on bed costs per annum would be realisable. Although it was not in the remit of this review, it is worth noting that surveillance of participants up to four years after randomisation to home or hospital regimens revealed no differences between groups (Grau 2001).

Regarding the results of quality of life outcomes reported in Bäckman 2004, Blattler 1998 (excluded from our review as it was not an RCT) observed a similar preference in two-thirds of participants, who challenged hospital confinement and stated that they would not choose hospitalisation another time. The Blattler trial also reported that its home treatment group was free of symptoms a day earlier and returned to work a week earlier than the hospital treatment group (Blattler 1998).

\section{AUTHORS' CONCLUSIONS}

\section{Implications for practice}

This review presents low-quality evidence suggesting that patients treated at home with low molecular weight heparin (LMWH) are less likely to have recurrence of venous thromboembolism (VTE) than those treated in hospital. Researchers have found no clear differences in major or minor bleeding complications, nor in mortality (low-quality evidence), indicating that treatment at home with LMWH is not more harmful than treatment in an inpatient setting with LMWH or unfractionated heparin (UFH). Despite the limitations of reviewed trials, low-quality evidence suggests that home treatment of patients with DVT is more effective than standard hospital treatment.

\section{Implications for research}

It is unlikely that definitive evidence on the safety of home treatment will be forthcoming for reasons addressed in the discussion. This is underscored by the fact that during our search, we identified no other high-quality randomised controlled trials published after 2005. Also, treatment of individuals with thromboembolism with LMWH is being incorporated into local health authority guidelines that include at-home administration practices (East Lancashire Health Economy 2015; Wong 2014). A larger database of accumulated uncontrolled studies that can be compared only with historical controls is needed. Anecdotal notes may describe treatment failure but as these occurrences will be rare, it is possible that they will not be published.

It has been suggested by Baron 1999 that patients should be allocated on a triage basis: (1) standard in-patient regimen for those with intercurrent illness or massive VTE; (2) partial home treatment for those receiving the diagnosis in hospital but fit enough for discharge; and (3) complete home treatment. The ideal trial would compare LMWH only in each arm, would exclude $25 \%$ or fewer participants from entry into the trial, and would present trial results in three groups. These issues should be given further examination.

Some practical issues remain to be resolved.

- Should the patient be admitted at all if suitable for home treatment?

- Should LMWH be given on suspicion or only on confirmation of the diagnosis?

- How would the treatment comparison be changed by use of newer direct oral anticoagulants versus more traditional LMWH?

- Should exclusion criteria be relaxed to favour greater entry to home treatment? For example, should a healthy pregnancy preclude home treatment?

- Should a screening test such as D-dimer levels be used?

- Should the system be controlled by the traditional physician's team, or should specialist anticoagulant nurses be trained? If so, will a lead clinician continue to accept overall responsibility?

- How should local guidelines be developed that include clinical prediction rules, biomarkers, and imaging that can be used to tailor therapy to disease severity?

- How should community healthcare workers be trained to administer treatment and monitor treatment progress?

\section{ACKNOWLEDGEMENTS}

We extend our acknowledgement to Ivor Schraibman, Elizabeth Royle, and Alan Milne for authoring the original draft of this review. We would like to thank Mayada Abu Affan for her contribution to the 2007 update of the review, and the Cochrane Vascular editorial base for support and assistance in updating this review. 


\section{RE F E R E N C E S}

\section{References to studies included in this review}

Bäckman 2004 \{published data only\}

Bäckman K, Carlsson P, Kentson M, Hansen S, Engquist L, Hallert C. Deep venous thrombosis: a new task for primary health care. Scandinavian Journal of Primary Health Care 2004;22(1):44-9.

\section{Boccalon 2000 \{published data only\}}

Boccalon H, Elias A, Chale JJ, Cadene A, Dumoulin A. Treatment of deep vein thrombosis at home: from theory to medical practice [French]. Bulletin de l'Academie Nationale de Medecine 1998;182(1):101-15.

* Boccalon H, Elias A, Chale JJ, Cadene A, Gabriel S. Clinical outcome and cost of hospital vs home treatment of proximal deep vein thrombosis with a low-molecular-weight heparin: the Vascular Midi-Pyrenees study. Archives of Internal Medicine 2000;160(12):1769-73.

\section{Chong 2005 \{published data only\}}

Chong $\mathrm{BH}$. A randomized, prospective, multicentre study comparing the efficacy, safety and cost of once-daily enoxaparin given at home with unfractionated heparin given in hospital in the treatment of deep-vein thrombosis. Blood 2002;100(11):Abstract 2772.

* Chong BH, Brighton TA, Baker RI, Thurlow P, Lee CH, ASTH DS Group. Once-daily enoxaparin in the outpatient setting versus unfractionated heparin in hospital for the treatment of symptomatic deep-vein thrombosis. Journal of Thrombosis and Thrombolysis 2005;19(3):173-81.

\section{Daskalopoulos 2005 \{published data only\}}

Daskalopoulos ME, Daskalopoulou SS, Tzortzis E, Sfiridis P, Nikolaou A, Dimitroulis D, et al. Long-term treatment of deep venous thrombosis with a low molecular weight heparin (tinzaparin): a prospective randomized trial. European Journal of Vascular and Endovascular Surgery 2005;29(6):638-50.

\section{Koopman 1996 \{published data only\}}

Koopman MMW, Prandoni P, Piovella F, Ockelford PA, Brandjes DPM, van der Meer J, et al. Treatment of patients with venous thrombosis with intravenous unfractionated heparin in hospital compared with subcutaneous low-molecular-weight heparin out of hospital. Annals of Hematology 1996;72:A3.

* Koopman MMW, Prandoni P, Piovella F, Ockelford PA, Brandjes DPM, van der Meer J, et al. Treatment of venous thrombosis with intravenous unfractionated heparin in hospital as compared with subcutaneous low molecular weight heparin at home. New England Journal of Medicine 1996;334(11):682-7.

van den Belt AGM, Bossuyt PMM, Prins MH, Gallus AS, Buller HR. Replacing inpatient care by outpatient care in the treatment of deep venous thrombosis - an economic evaluation. Thrombosis and Haemostasis 1998;79:259-62.
Levine 1996 \{published data only\}

* Levine M, Gent M, Hirsch J, Leclerc J, Anderson D, Weitz J, et al. A comparison of low molecular weight heparin administered primarily at home with unfractionated heparin administered in the hospital for proximal deep vein thrombosis. New England Journal of Medicine 1996;334:677-82.

O'Brien B, Levine M, Willan A, Goeree R, Haley S, Blackhouse G, et al. Economic evaluation of outpatient treatment with lowmolecular-weight-heparin for proximal vein thrombosis. Archives of Internal Medicine 1999;159:2298-304.

\section{Ramacciotti 2004 \{published data only\}}

Ramacciotti E, Araujo GR, Lastoria S, Dietrich F, Maffei FH, Mussi NS. The efficacy and safety of enoxaparin once-daily given partly at home, compared with unfractionated heparin given in the hospital in the treatment of proximal deep-vein thrombosis, a Brazilian multicenter study. Blood 2001;98(11):Abstract 4026.

Ramacciotti E, Araujo GR, Lastoria S, Maffei FH, Dietrich F. An open-label, comparative study of the efficacy and safety of an outpatient single daily dose of enoxaparin versus unfractionated heparin in the treatment of proximal lower limb deep-vein thrombosis. Blood 2002;11:503a-Abstract 1960.

Ramacciotti E, Araujo GR, Lastoria S, Maffei FH, DietrichNeto F, CLETRAT Investigators. Efficacy and safety of oncedaily enoxaparin given in the outpatient setting compared with in-hospital unfractionated heparin for treatment of proximal lower limb deep-vein thrombosis. Journal of Thrombosis and Haemostasis 2003;1(Suppl 1):Abstract P1401.

* Ramacciotti E, Araujo GR, Lastoria S, Maffei FH, Karaoglan DM, Michaelis W, et al. An open-label, comparative study of the efficacy and safety of once-daily dose of enoxaparin versus unfractionated heparin in the treatment of proximal lower limb deep-vein thrombosis. Thrombosis Research 2004;114(3):149-53.

\section{References to studies excluded from this review}

Aujesky 2011 \{published data only\}

Aujesky D, Roy PM, Verschuren F, Righini M, Osterwalder J, Egloff $M$, et al. An international, randomized noninferiority trial of outpatient versus inpatient treatment for pulmonary embolism. Journal of General Internal Medicine 2011;26(10):1220.

* Aujesky D, Roy PM, Verschuren F, Righini M, Osterwalder J, Egloff M, et al. Outpatient versus inpatient treatment for patients with acute pulmonary embolism: an international, open-label, randomised, non-inferiority trial. Lancet 2011;378(9785):41-8.

\section{Belcaro 1999 \{published data only\}}

Belcaro G, Nicolaides AN, Cesarone MR, Laurora G, De Sanctis MT, Incandela L, et al. Comparison of low molecular weight heparin, administered primarily at home, with unfractionated heparin, administered in hospital, and 
subcutaneous heparin, administered at home for deep-vein thrombosis. Angiology 1999;50(10):781-7.

\section{Blattler 1998 \{published data only\}}

Blattler W, Borer W, Linder C. Outpatient and conventional treatment of acute deep vein thrombosis evaluated in a controlled single-centre study. Phlébologie 1998;51(1):41-6.

Blattler W, Borer W, Linder C, Bergan J. Outpatient and conventional treatment of acute deep vein thrombosis evaluated in a controlled single-centre study [Traitements ambulatoire et conventionnel de la thrombose veineuse profonde aigue: Bilan monocentrique]. Phlébologie 1998;51(1):33-9.

\section{Buller 2004 \{published data only\}}

Buller $\mathrm{H}$. Initial outpatient treatment of venous thromboembolism with Fondaparinux (Arixtra ${ }^{\circledR}$ ): the MATISSE trials. Journal of Thrombosis and Haemostasis. 2005; Vol. 3 , issue 1:Abstract P1112.

Buller HR, The Matisse Investigators. Initial outpatient treatment of venous thromboembolism with fondaparinux (Arixtra(R)): the MATISSE trials. Blood. 104 2004; Vol. 104, issue 11:Abstract 705.

\section{Conner 1999 \{unpublished data only\}}

Conner C. Innohep User's meeting, Windsor. Data on file 1999.

\section{Fitzmaurice 2000 \{published data only\}}

Fitzmaurice DA, Hobbs FD, Murray ET, Holder RL, Allan TF, Rose $\mathrm{PE}$. Oral anticoagulation management in primary care with the use of computerised decision support and near-patient testing: a randomised, controlled trial. Archives of Internal Medicine 2000;160(15):2343-8.

\section{Frank 1998 \{published data only\}}

Frank D, Blattler W. Comparison of ambulatory and inpatient treatment of acute deep venous thrombosis of the leg: subjective and economic aspects [German]. Schweizerische Medizinische Wochenschrift. Journal Suisse de Medecine 1998;128(36):1328-33.

\section{Goldhaber 1998 \{published data only\}}

Goldhaber SZ, Morrison RB, Diran LL, Creager MA, Lee TH. Abbreviated hospitalisation for deep vein thrombosis with the use of ardeparin. Archives of Internal Medicine 1998;158(21):2325-8.

\section{Grau 1998 \{published data only\}}

Grau E, Real E, Pastor E, Viciano V, Aguilo J. Home treatment of deep vein thrombosis: a two-years experience of a single institution. Haematologica 1998;83(5):438-41.

\section{Grau 2001 \{published data only\}}

Grau E, Tenias JM, Real E, Medrano J, Ferrer R, Pastor E, et al. Home treatment of deep vein thrombosis with low molecular weight heparin: long-term incidence of recurrent venous thromboembolism. American Journal of Haematology 2001;67(1):10-4

\section{Green 1998 \{published data only\}}

Green ES, Rhodes S, Bond S, Thomson S, Troughton AH. Outpatient treatment of deep vein thrombosis using low molecular weight heparin. British Journal of Haematology 1998;101(Suppl 1):Abstract 234.

\section{Hull 2000 \{published data only\}}

Hull RD, Pineo GF, Francis C, Bergqvist D, Fellenius C, Soderberg K, et al. Low-molecular-weight heparin prophylaxis using dalteparin extended out-of-hospital vs in-hospital warfarin/out-of-hospital placebo in hip arthroplasty patients: a double-blind, randomized comparison. North American Fragmin Trial Investigators. Archives of Internal Medicine 2000;160(14):2208-15.

\section{Hull 2002 \{published data only\}}

Hull RD, Pineo GF, Mah AF. Does rebound exist? A comparison of venous thromboembolic (VTE) event rates in the post-treatment period for patients randomized to long-term low-molecularweight heparin (LMWH) versus warfarin sodium. Blood. 100 2002; Vol. 100, issue 11:Abstract 1951.

Hull 2009 \{published data only\}

Hull RD, Pineo GF, Brant R, Liang J, Cook R, Solymoss S, et al. Home therapy of venous thrombosis with long-term LMWH versus usual care: patient satisfaction and post-thrombotic syndrome. American Journal of Medicine 2009;122(8):762-9.

\section{Lindmarker 1996 \{published data only\}}

Lindmarker P, Holstrom M. Use of low molecular weight heparin (dalteparin), once daily, for the treatment of deep vein thrombosis. A feasibility and health economic study in an outpatient setting. Swedish Venous Thrombosis Dalteparin Trial Group. Journal of Internal Medicine 1996;240(6):395-401.

Miles 1998 \{published data only\}

Miles J, O'Shaugnessey D, Wimperis J. Outpatient management of DVT in the United Kingdom. Presentation to American Thoracic Society. 1998.

\section{Modesto-Alapont 2006 \{published data only\}}

Modesto-Alapont M, Nauffal-Manzur D, Nsotegui-Barrera E, Menendez-Villanueva R, Ballesta A, Touza R, et al. Can home prophylaxis for venous thromboembolism reduce mortality rates in patients with chronic obstructive pulmonary disease? [Spanish]. Archivos de Bronconeumologia 2006;42(3):130-4.

\section{O'Shaugnessy 1998 \{published data only\}}

O'Shaughnessy DF, Tovey C, Miller ALC, O'Neill V, Rana PS, Akbar S, et al. Outpatient management of deep vein thrombosis. Journal of Accident and Emergency Medicine 1998;15(5):292-3.

\section{Otero 2010 \{published data only\}}

Anon. Home treatment of pulmonary embolism. http:// clinicaltrials.gov/show/NCT00214929. 2005.

Otero R, Uresandi F, Jiménez D, Cabezudo MA, Oribe M, Nauffal D, et al. Home treatment in pulmonary embolism. Thrombosis Research 2010;126(1):e1-e5. 
Pineo 2003 \{published data only\}

Pineo GF, Hull RD, Mah AF, Lite I. Does rebound exist? A comparison of venous thromboembolic event rates in the post-treatment period for patients randomized to long-term low-molecular-weight heparin vs. warfarin sodium. Journal of Thrombosis and Haemostasis 2003;1(Suppl 1):Abstract P1882.

\section{Rymes 2002 \{published data only\}}

Rymes NL, Lester W, Connor C, Chakrabati S, Fegan CD. Outpatient management of DVT using LMWH and a hospital outreach service. Clinical and Laboratory Haematology 2002;24(3):165-70.

\section{Ting 1998 \{published data only\}}

Ting SBN, Ziegenbein RW, Gan TE, Catalano JV, Monagle P, Silvers J, et al. Dalteparin for deep vein thrombosis: a hospital-in-the-home program. Medical Journal of Australia 1998;168(6):272-6.

\section{Wells 1998 \{published data only\}}

Wells PS, Kovacs MJ, Bormanis J, Forgie MA, Goudie D, Morrow B, et al. Expanding eligibility for outpatient treatment of deep vein thrombosis and pulmonary embolism with lowmolecular-weight heparin: a comparison of patient selfinjection with homecare injection. Archives of Internal Medicine 1998;158(16):1809-12.

\section{White 1989 \{published data only\}}

White RH, McCurdy SA, von Marensdorff H, Woodruff DEJ, Leftgoff $L$. Home prothrombin time monitoring after the initiation of warfarin therapy. A randomised, prospective study. Annals of Internal Medicine 1989;111(9):730-7.

\section{Wilson 2003 \{published data only\}}

Wilson SJ, Wells PS, Kovacs MJ, Lewis GM, Martin J, Burton E, et al. Comparing the quality of oral anticoagulant management by anticoagulation clinics and by family physicians: a randomized controlled trial. Canadian Medical Association Journal 2003;169(4):293-8.

\section{Wimperis 1998 \{published data only\}}

Wimperis JZ, Pout G, Dilks G, Wilson P, Clarke J, Jenkins P, et al. Significant bed savings resulting from outpatient management of deep vein thrombosis with low molecular weight heparin. British Journal of Haematology 1998;101(Suppl 1):Abstract 231.

\section{Additional references}

\section{Ageno 2005}

Ageno W, Grimwood R, Limbiati S, Dentali F, Steidl L, Wells PS. Home-treatment of deep vein thrombosis in patients with cancer. Haematologica 2005;90(2):220-4.

\section{Atkins 2004}

Atkins D, Best D, Briss PA, Eccles M, Falck-Ytter Y, Flottorp S, et al. GRADE Working Group. Grading quality of evidence and strength of recommendations. BMJ 2004;328(7454):1490-4.

\section{Bakker 1988}

Bakker M, Dekker PJ, Knot EA, van Bergen PF, Jonker JJ. Home treatment for deep venous thrombosis with low molecular weight heparin [letter]. Lancet 1988;2:1142.

\section{Baron 1999}

Baron RM, Goldhaber SZ. Deep venous thrombosis: early discharge strategies and outpatient management. Journal of Thrombosis and Thrombolysis 1999;7(2):113-22.

\section{East Lancashire Health Economy 2015}

East Lancashire Medicines Management Board. Use of Low Molecular Weight Heparins (LMWH) (e.g. Tinzaparin) in Primary Care: Best Practice Guideline. www.elmmb.nhs.uk/policies-andguidelines/guidelines/ (accessed 20 June 2017); Vol. Version 3.

\section{Erkens 2010}

Erkens PMG, Prins MH. Fixed dose subcutaneous low molecular weight heparins versus adjusted dose unfractionated heparin for venous thromboembolism. Cochrane Database of Systematic Reviews 2010, Issue 9. [DOI: 10.1002/14651858.CD001100.pub3]

\section{Finks 2016}

Finks SW, Trujillo TC, Dobesh PP. Management of venous thromboembolism. Annals of Pharmacotherapy 2016;50(6):486-501.

\section{GRADEProGDT 2015 [Computer program]}

McMaster University (developed by Evidence Prime). GRADEpro GDT. Version accessed 11 July 2017. Hamilton (ON): McMaster University (developed by Evidence Prime), 2015.

\section{Griffin 1996}

Griffin J. Deep venous thrombosis and pulmonary embolism. London: Office of Health Economics, 1996.

\section{Higgins 2011}

Higgins JPT, Green S (editors). Cochrane Handbook for Systematic Reviews of Interventions. Version 5.1.0 (updated March 2011). The Cochrane Collaboration, 2011. Available from www.handbook.cochrane.org.

\section{Hyers 2007}

Hyers TM, Spyropoulos AC, for the INNOVATE Investigators. Community-based treatment of venous thromboembolism with a low-molecular-weight heparin and warfarin. Journal of Thombosis and Thombolysis 2007;24(3):225-32.

\section{Jadad 1996}

Jadad AR, Moore RA, Carroll D, Jenkinson C, Reynolds DJ, Gavaghan DJ, et al. Assessing the quality of reports of randomized clinical trials: is blinding necessary?. Controlled Clinical Trials 1996;17(1):1-12.

\section{Leizorovicz 1994}

Leizorovicz A, Simmoneau G, Decousus H, Boissel JP. Comparison of efficacy and safety of low molecular weight heparins and unfractionated heparin in initial treatment of deep vein thrombosis: a meta-analysis. BMJ 1994;309:299-304. 


\section{Lensing 1995}

Lensing AW, Prins MH, Davidson BL, Hirsh J. Treatment of deep venous thrombosis with low-molecular-weight heparins. A meta-analysis. Archives of Internal Medicine 1995;155(6):601-7.

\section{NICE 2012}

National Institute for Health and Care Excellence (NICE). Venous thromboembolic diseases: diagnosis, management and thrombophilia testing (CG144). www.nice.org.uk/guidance/ CG144 (accessed 20 June 2017).

\section{O'Brien 1999}

O'Brien B, Levine M, Willan A, Goeree R, Haley S, Blackhouse G, et al. Economic evaluation of outpatient treatment with lowmolecular-weight-heparin for proximal vein thrombosis. Archives of Internal Medicine 1999;159:2298-304.

\section{RevMan 2014 [Computer program]}

The Nordic Cochrane Centre, The Cochrane Collaboration. Review Manager (RevMan). Version 5.3. Copenhagen: The Nordic Cochrane Centre, The Cochrane Collaboration, 2014.

\section{Robertson 2015}

Robertson L, Kesteven P, McCaslin JE. Oral direct thrombin inhibitors or oral factor Xa inhibitors for the treatment of deep vein thrombosis. Cochrane Database of Systematic Reviews 2015, Issue 6. [DOI: 10.1002/14651858.CD010956.pub2]

\section{Robertson 2017}

Robertson L, Jones LE. Fixed dose subcutaneous low molecular weight heparins versus adjusted dose unfractionated heparin for the initial treatment of venous thromboembolism. Cochrane Database of Systematic Reviews 2017;Issue 2:Art. No.: CD001100.

\section{Ryan 2016}

Ryan R, Hill S. How to GRADE the quality of the evidence. Cochrane Consumers and Communication Group, June 2016. Version 1.0. http://cccrg.cochrane.org/author-resources (accessed 13 August 2017)..

\section{CHARACTERISTICS OF STUDIES}

Characteristics of included studies [ordered by study ID]

\section{van den Belt 1998}

van den Belt AGM, Bossuyt PMM, Prins MH, Gallus AS, Buller HR. Replacing inpatient care by outpatient care in the treatment of deep venous thrombosis - an economic evaluation. Thrombosis and Haemostasis 1998;79:259-62.

\section{van Es 2014}

van Es N, Coppens M, Schulman S, Middeldorp S, Büller HR. Direct oral anticoagulants compared with vitamin $\mathrm{K}$ antagonists for acute venous thromboembolism: evidence from phase 3 trials. Blood 2014;124:1968-75.

\section{Wong 2014}

Wong M, Butt IL, on behalf of Wirral Drug and Therapeutics Committee. Low Molecular Weight Heparin Prescribing and Administration (Adults). http:// mm.wirral.nhs.uk/document_uploads/guidelines/ LMWHprescribingandadministrationv1a.pdf.. Version: v1a 2014 (accessed 13 July 2017).

\section{Zelen 1979}

Zelen M. A new design for randomized clinical trials. New England Journal of Medicine 1979;300:1242-5.

\section{References to other published versions of this review}

\section{Othieno 2007}

Othieno R, Abu Affan M, Okpo E. Home versus inpatient treatment for deep vein thrombosis. Cochrane Database of Systematic Reviews 2007, Issue 3. [DOI: 10.1002/14651858.CD003076.pub2]

\section{Schraibman 2001}

Schraibman IG, Milne AA, Royle EM. Home versus inpatient treatment for deep vein thrombosis. Cochrane Database of Systematic Reviews 2001, Issue 2. [DOI: 10.1002/14651858.CD003076]

* Indicates the major publication for the study

Boccalon 2000

$\begin{array}{ll}\text { Methods } & \text { Study design: randomised controlled trial } \\ & \text { Exclusions post randomisation: One patient withdrew consent following randomisation, } 7 \text { withdrew } \\ \text { owing to severe complications (3 DVT extensions, } 4 \text { major haemorrhages). } \\ \text { Losses to follow-up: } 38 \text { participants did not complete the 6-month follow-up (those treated in hospital } \\ \text { were twice as likely to withdraw). } \\ \text { Intention-to-treat analysis: not indicated } \\ \text { Country: France } \\ \text { Setting: home or hospital } \\ \mathrm{N}: 204 \text { randomised, } 201 \text { included (102 hospital, } 99 \text { home), representing } 11.8 \% \text { of those eligible }\end{array}$


Sex: 113 male; 88 female

Inclusion criteria: confirmed diagnosis (by ultrasonography or venography) of proximal DVT not more than 30 days before enrolment

Exclusion criteria: thrombus in the inferior vena cava, a floating thrombus, history of DVT within the previous 6 months, DVT with symptomatic PE, a clinical condition requiring hospitalisation, contraindication to anticoagulant treatment, pregnancy, heparin treatment within the 48 hours preceding inclusion, home or hospital treatment impossible for any reason, participant lived too far away from the trial centre, written consent not given

Participants were also examined, although not necessarily excluded, for risk factors for DVT, including previous thromboembolism, varicose veins, immobilisation, surgery, trauma, cancer, use of oral contraceptives, known or inherited clotting disorders, other comorbidities such as cardiovascular disease with right ventricular failure

Treatment: sc injection of LMWH (dalteparin sodium, enoxaparin sodium, or nadroparin calcium, as chosen by the attending physician) at the recommended dose, followed by anticoagulant for 6 months at home

Control: sc injection of LMWH (dalteparin sodium, enoxaparin sodium, or nadroparin calcium, as chosen by the attending physician) at the recommended dose, followed by anticoagulant for 6 months initially in hospital for $10 \pm 2$ days, then at home

Anticoagulants: oral VKA or fluindione, $20 \mathrm{mg} / \mathrm{d}$ for the first 3 days, followed by regimen to maintain INR between 2.0 and 3.0 for up to 6 months

Participants were also given compression stockings and were encouraged to return to physical activity according to a schedule approved by general practitioner and nurse.

$\begin{array}{ll}\text { Outcomes } & \text { Primary: recurrent VTE, PE, major bleeding } \\ & \text { Secondary: death, minor bleeding, economic analysis } \\ & \text { Duration of follow-up: } 6 \text { months }\end{array}$

Notes

\section{Risk of bias}

Bias Authors' judgement Support for judgement

\begin{tabular}{|c|c|c|}
\hline $\begin{array}{l}\text { Random sequence genera- } \\
\text { tion (selection bias) }\end{array}$ & Unclear risk & Not stated \\
\hline $\begin{array}{l}\text { Allocation concealment } \\
\text { (selection bias) }\end{array}$ & Low risk & Sealed envelopes were used. \\
\hline $\begin{array}{l}\text { Blinding of participants } \\
\text { and personnel (perfor- } \\
\text { mance bias) } \\
\text { All outcomes }\end{array}$ & Low risk & $\begin{array}{l}\text { Although no blinding of participant or personnel was reported, both groups re- } \\
\text { ceived the same treatment. All participants received an oral anticoagulant for } \\
\text { the first } 3 \text { days. Outcome is unlikely to have been affected by lack of blinding } \\
\text { of participants or personnel. }\end{array}$ \\
\hline
\end{tabular}

\begin{tabular}{lll}
\hline $\begin{array}{l}\text { Blinding of outcome as- } \\
\text { sessment (detection bias) }\end{array}$ & High risk & $\begin{array}{l}\text { Blinding of outcome assessors was not reported. Outcomes could have been } \\
\text { influenced by lack of blinding. }\end{array}$
\end{tabular}

All outcomes

\begin{tabular}{|c|c|c|}
\hline $\begin{array}{l}\text { Incomplete outcome data } \\
\text { (attrition bias) }\end{array}$ & High risk & $\begin{array}{l}38 \text { participants did not complete the } 6 \text {-month follow-up (those treated in hos- } \\
\text { pital were twice as likely to withdraw). }\end{array}$ \\
\hline
\end{tabular}
All outcomes 
Boccalon 2000 (Continued)
Selective reporting (re-
Low risk
All prespecified outcomes were reported. porting bias)

Other bias

Low risk

No other potential bias was identified.

\section{Bäckman 2004}

Study design: randomised multi-centre trial
Exclusions post randomisation: 7 patients excluded (5 randomised to in-patient treatment refused to
co-operate; 2 randomised to outpatient/home treatment had a drug reaction and haematuria, respec-
tively)
Losses to follow-up: none
Intention-to-treat analysis: yes

\section{Participants}

Country: Sweden

Setting: in-patient or out-patient/home

$\mathrm{N}$ : 224 met inclusion criteria, 131 randomised (66 in-patient, 65 out-patient/home), representing $58 \%$ of those eligible

Age: mean 66 (33 to 87 ) years, in-patient group; 67 (25 to 91) years, out-patient/home group

Sex, male/female ratio: 34/34 in-patient group; 34/31 out-patient group

Inclusion criteria: acute symptomatic DVT confirmed by phlebography or ultrasound in patients aged 18 years and older presenting at the emergency department

Exclusion criteria: not clearly stated

Interventions All participants were provided with intervention stockings. Both groups were treated with LMWH administered sc once daily, adjusted for body weight, for at least 5 days until prothrombin time was $<25 \%$ $($ INR $>2.0)$ for at least 1 day.

Out-patient/home: Treatment included a daily visit to the out-patient department at a primary care centre or a visit by the district nurse at the participant's home, depending on local circumstances or patient preference.

In-patient: Participants were admitted to the ward.

$\begin{array}{ll}\text { Outcomes } & \text { Direct medical and direct non-medical costs } \\ & \text { Duration of follow-up: } 3 \text { months }\end{array}$

Notes

\section{Risk of bias}

Bias Authors' judgement Support for judgement

Random sequence genera- Unclear risk The method used to generate the random sequence was not described by trial tion (selection bias) authors.

\begin{tabular}{|c|c|c|}
\hline $\begin{array}{l}\text { Allocation concealment } \\
\text { (selection bias) }\end{array}$ & Low risk & $\begin{array}{l}\text { Randomisation was performed centrally by means of codes in envelopes in } \\
\text { batches of } 20 \text {. in accordance with Zelen } 1979 .\end{array}$ \\
\hline
\end{tabular}




\section{Bäckman 2004 (Continued)}

Blinding of participants and personnel (perfor-

Low risk mance bias)

All outcomes
Although participants were allowed to change their assigned treatment or to leave the study after randomisation, the review authors determined that the risk of performance bias was low.

\begin{tabular}{lll}
\hline $\begin{array}{l}\text { Blinding of outcome as- } \\
\text { sessment (detection bias) } \\
\text { All outcomes }\end{array}$ & High risk & Not described; outcom \\
\hline $\begin{array}{l}\text { Incomplete outcome data } \\
\text { (attrition bias) }\end{array}$ & Low risk & \\
All outcomes & &
\end{tabular}

\begin{tabular}{lll}
\hline $\begin{array}{l}\text { Selective reporting (re- } \\
\text { porting bias) }\end{array}$ & Low risk & \\
\hline Other bias & Unclear risk & $\begin{array}{l}\text { Information was insufficient to reveal whether other potential bias exists; only } \\
40 \% \text { of participants randomised to treatment with LMWH were actually treat- } \\
\text { ed at home. }\end{array}$ \\
\end{tabular}

\section{Chong 2005}

Study design: randomised parallel-group open study
Exclusions post randomisation: $63(20 \%)$ were not included in the primary outcome analysis
Losses to follow-up: 45 had no analysis at 24 weeks
Intention-to-treat analysis: yes

Participants
Setting: out-patient or hospital
N: 301 enrolled; 298 randomised (148 hospital, 150 home)
Age: $18+$ years
Sex: 156 male, 142 female
Inclusion criteria: diagnosis of symptomatic lower extremity DVT (proximal or distal) confirmed by con-
trast venography and/or ultrasonography, suitable for treatment in an out-patient setting, prepared to
self-administer daily sc injections, life expectancy $>6$ months
Exclusion criteria: received therapeutic doses of heparin for more than 24 hours before randomisation;
clinically overt signs or symptoms of PE or evidence of PE on lung scanning or pulmonary angiogra-
phy; impending venous gangrene; previous HIT or another hypersensitivity reaction to heparin; platelet
count < $50 \times 109 /$ L; treatment with fibrinolytics or oral anticoagulants within the previous 5 days, or
with other investigational therapeutic agents within the previous 4 weeks; pregnancy or lactation; any
clinically significant medical condition other than DVT that would prevent discharge from hospital

Interventions

Treatment: once-daily sc injection of LMWH enoxaparin $1.5 \mathrm{mg} / \mathrm{kg}$ for a minimum of 5 days plus $10 \mathrm{mg}$ of warfarin for 3 months with dose adjusted to achieve and maintain INR above 2 and within range accepted by the investigator

Control: 5000 IU bolus of UFH for a minimum of 5 days, plus $10 \mathrm{mg}$ warfarin started on day 1 of treatment, for 3 months 
Duration of follow-up: 24 weeks

\section{Notes}

\section{Risk of bias}

\begin{tabular}{|c|c|c|}
\hline Bias & Authors' judgement & Support for judgement \\
\hline $\begin{array}{l}\text { Random sequence genera- } \\
\text { tion (selection bias) }\end{array}$ & Unclear risk & Did not report use of adequate random sequence generation \\
\hline $\begin{array}{l}\text { Allocation concealment } \\
\text { (selection bias) }\end{array}$ & Unclear risk & Did not report use of adequate concealment technique \\
\hline $\begin{array}{l}\text { Blinding of participants } \\
\text { and personnel (perfor- } \\
\text { mance bias) } \\
\text { All outcomes }\end{array}$ & High risk & Treatment was not blinded. \\
\hline $\begin{array}{l}\text { Blinding of outcome as- } \\
\text { sessment (detection bias) } \\
\text { All outcomes }\end{array}$ & Low risk & $\begin{array}{l}\text { Assessors were independent of the study and investigators and were unaware } \\
\text { of the treatments that participants were receiving. }\end{array}$ \\
\hline $\begin{array}{l}\text { Incomplete outcome data } \\
\text { (attrition bias) } \\
\text { All outcomes }\end{array}$ & Low risk & All outcome data were reported. \\
\hline $\begin{array}{l}\text { Selective reporting (re- } \\
\text { porting bias) }\end{array}$ & Low risk & All prespecified primary and secondary safety endpoints were reported. \\
\hline Other bias & Unclear risk & $\begin{array}{l}\text { Information was insufficient to reveal whether other potential bias exists; only } \\
23 \% \text { of participants randomised to treatment with LMWH were actually treat- } \\
\text { ed exclusively at home. }\end{array}$ \\
\hline
\end{tabular}

Daskalopoulos 2005

Methods Study design: prospective randomised trial

Exclusions post randomisation: 6 patients withdrew consent following randomisation

Losses to follow-up: none

Intention-to-treat analysis: yes

Country: Greece
Setting: out-patient or hospital
N: 108 randomised ( $55 \mathrm{LMWH}, 53 \mathrm{UFH})$
Age: 18 years and over, range 23 to 95 , mean 58.6 years
Sex: 61 female, 41 male


Daskalopoulos 2005 (Continued)

Inclusion criteria: acute proximal DVT confirmed by colour duplex ultrasound scan not more than 1 week from onset

Exclusion criteria: segmental DVT restricted to infrapopliteal deep veins or calf muscles, as determined by duplex ultrasonography; symptomatic or clinically suspected PE; history of recently diagnosed (within 12 months) DVT or PE; already receiving anticoagulant therapy; bleeding tendency objectively confirmed; hypersensitivity to heparin preparations or coumarin derivatives; uncontrolled hypertension; history of recently diagnosed (less than 1 month) cerebrovascular accident, intracranial artery aneurysm, infectious endocarditis, thrombocytopenia, active peptic ulcer, hepatic or renal failure, history of asthma, recent spinal or epidural anaesthesia, or intraspinal paracentesis (less than 5 days); recent surgery (less than 5 days); recently performed thrombolysis or receiving antiplatelet therapy; body weight less than $35 \mathrm{~kg}$; pregnancy; illicit drug addiction; altered mental status or impaired cognitive function with inability to comply with study protocol

Interventions

Treatment: single sc injection of LMWH (tinzaparin sodium) at a weight-adjusted dose (175 anti Xa IU/ $\mathrm{Kg}$ ) daily for 6 months

Control: iv bolus of 5000 IU UFH followed by iv infusion of UFH for 5 to 7 days. APTT was measured after 4 hours of initiation of heparin administration and was repeated 6 hours thereafter to reach the therapeutic range (ratio: 1.5 to 2.5 ).

Oral anticoagulant was commenced on the third day following UFH therapy.

Outcomes Primary: recanalisation of thrombosed veins, major events

Secondary: recurrent DVT, PE, major bleeding, minor bleeding, thrombocytopenia, death

Duration of follow-up: 12 months

\section{Notes}

\section{Risk of bias}

\begin{tabular}{|c|c|c|}
\hline Bias & Authors' judgement & Support for judgement \\
\hline $\begin{array}{l}\text { Random sequence genera- } \\
\text { tion (selection bias) }\end{array}$ & Low risk & Randomisation was done by means of a computer schedule. \\
\hline $\begin{array}{l}\text { Allocation concealment } \\
\text { (selection bias) }\end{array}$ & Unclear risk & Not reported \\
\hline $\begin{array}{l}\text { Blinding of participants } \\
\text { and personnel (perfor- } \\
\text { mance bias) } \\
\text { All outcomes }\end{array}$ & High risk & Study was open-label. \\
\hline $\begin{array}{l}\text { Blinding of outcome as- } \\
\text { sessment (detection bias) } \\
\text { All outcomes }\end{array}$ & Low risk & $\begin{array}{l}\text { Because a double-blind study was not feasible, all objective diagnostic tests } \\
\text { were interpreted by specialists including Coagulation Unit staff and Radiology } \\
\text { staff who were not involved in the study. }\end{array}$ \\
\hline $\begin{array}{l}\text { Incomplete outcome data } \\
\text { (attrition bias) } \\
\text { All outcomes }\end{array}$ & Low risk & All outcome data were reported. \\
\hline $\begin{array}{l}\text { Selective reporting (re- } \\
\text { porting bias) }\end{array}$ & Low risk & All predefined data endpoints were reported. \\
\hline Other bias & Low risk & No other potential bias was identified. \\
\hline
\end{tabular}




Study design: randomised controlled trial
Exclusions post randomisation: 2 (both withdrew consent, 1 from each group)
Losses to follow-up: 2 participants in each group were lost to follow-up at 12 weeks
Intention-to-treat analysis: yes

Countries: The Netherlands, France, Italy, New Zealand, Australia
Setting: home or hospital
N: 400 randomised (202 LMWH, 198 UFH)
Age: $59 \pm 17$ years LMWH group, $62 \pm 16$ years UFH group
Sex: 203 male; 197 female
Inclusion criteria: acute symptomatic proximal DVT proven by venography or duplex scan
Exclusion criteria: VTE within previous 2 years, suspected PE at presentation, geographic inaccessibili-
ty, PTS, less than 18 years old, pregnancy, life expectancy less than 6 months, previous treatment with
heparin for longer than 24 hours

Interventions

Treatment: twice-daily injections of LMWH (nadroparin calcium (Fraxiparine) at a dose adjusted for participant's weight) at home when appropriate; participants were instructed by nurse on how to administer the injections themselves

Control: UFH (APTT adjusted dose, continuous iv infusion of 1250 IU per hour after initial iv bolus of 5000 IU) in hospital

Duration: minimum 5 days, maximum 24 weeks

Oral anticoagulation: Warfarin commenced on day 1 and continued for 3 months, with dose adjusted to attain INR 2.0 to 3.0

Primary: symptomatic recurrent VTE
Secondary: major haemorrhage, death, quality of life comparisons, comparison of costs (in-patient vs
home)
Duration of follow-up: 6 months

Notes

\section{Risk of bias}

\begin{tabular}{lll}
\hline Bias & Authors' judgement & Support for judgement \\
\hline $\begin{array}{l}\text { Random sequence genera- } \\
\text { tion (selection bias) }\end{array}$ & Unclear risk & Method of random sequence generation was not reported. \\
\hline $\begin{array}{l}\text { Allocation concealment } \\
\text { (selection bias) }\end{array}$ & Low risk & Allocation was performed by means of a central 24-hour telephone service. \\
\hline $\begin{array}{l}\text { Blinding of participants } \\
\text { and personnel (perfor- } \\
\text { mance bias) }\end{array}$ & High risk & Unblinded trial \\
All outcomes & & \\
\hline
\end{tabular}


Koopman 1996 (Continued)

Blinding of outcome as- Low risk Objective testing was done blindly; documentation of all potential outcome sessment (detection bias)

All outcomes

\section{events was assessed by an independent adjudication committee whose mem-} bers were unaware of treatment assignments,

Incomplete outcome data Low risk All losses to follow-up were reported.

(attrition bias)

All outcomes

Selective reporting (re- Low risk All prespecified outcome measures were reported.

porting bias)

Other bias Unclear risk

Information was insufficient to determine whether other potential bias exists; only $36 \%$ of participants randomised to treatment with LMWH were actually treated at home.

Levine 1996

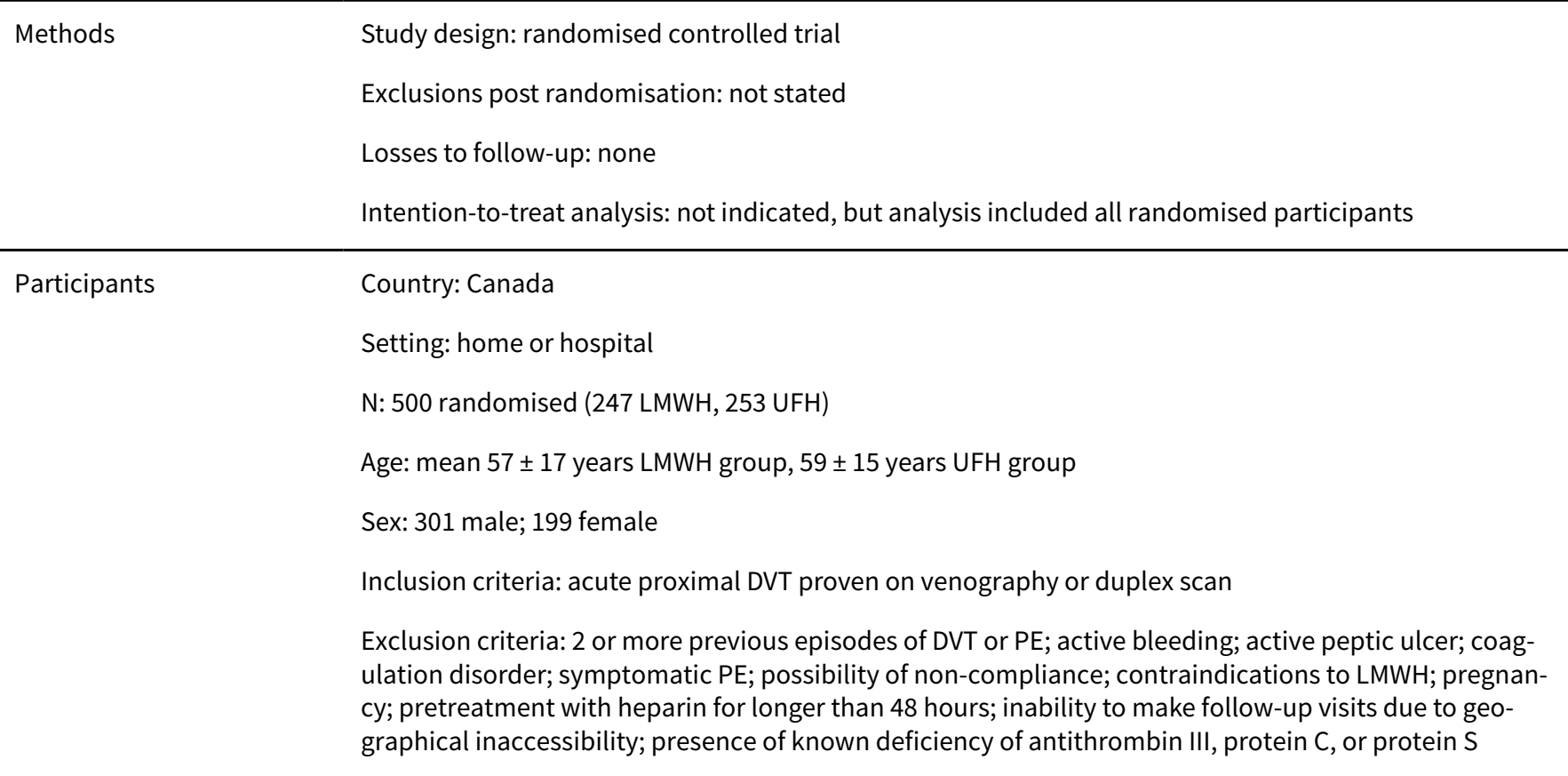

Interventions

Treatment: sc LMWH (enoxaparin $1 \mathrm{mg}$ per kg body weight twice a day) primarily at home

Control: UFH (APTT adjusted dose, continuous iv infusion of 20,000 IU after initial iv bolus of $5000 \mathrm{IU}$ ) in hospital

Duration: minimum 5 days

Anticoagulants: Warfarin sodium was started on evening of day 2 and was continued for at least 3 months. First dose of $10 \mathrm{mg}$ was thereafter adjusted to maintain INR between 2.0 and 3.0.

Outcomes Primary: symptomatic recurrent DVT or PE within 90 days of randomisation, major bleeding, minor bleeding during study period and up to 48 hours after discontinuation of study medication

Secondary: death, economic evaluation

Duration of follow-up: 3 months 
Levine 1996 (Continued)

Notes

\section{Risk of bias}

\begin{tabular}{|c|c|c|}
\hline Bias & Authors' judgement & Support for judgement \\
\hline $\begin{array}{l}\text { Random sequence genera- } \\
\text { tion (selection bias) }\end{array}$ & Unclear risk & Method of random sequence generation was not reported. \\
\hline $\begin{array}{l}\text { Allocation concealment } \\
\text { (selection bias) }\end{array}$ & Low risk & Treatment was assigned over the telephone from a central site. \\
\hline $\begin{array}{l}\text { Blinding of participants } \\
\text { and personnel (perfor- } \\
\text { mance bias) } \\
\text { All outcomes }\end{array}$ & High risk & Unblinded \\
\hline $\begin{array}{l}\text { Blinding of outcome as- } \\
\text { sessment (detection bias) } \\
\text { All outcomes }\end{array}$ & Low risk & $\begin{array}{l}\text { Testing and assessment for recurrent VTE and bleeding were conducted by a } \\
\text { committee unaware of treatment assignments. }\end{array}$ \\
\hline $\begin{array}{l}\text { Incomplete outcome data } \\
\text { (attrition bias) } \\
\text { All outcomes }\end{array}$ & Low risk & No losses to follow-up were reported. \\
\hline $\begin{array}{l}\text { Selective reporting (re- } \\
\text { porting bias) }\end{array}$ & Low risk & All prespecified outcomes were reported. \\
\hline Other bias & Unclear risk & $\begin{array}{l}\text { Information was insufficient to determine whether other potential bias exists; } \\
\text { only } 48.5 \% \text { of participants randomised to treatment with LMWH were actually } \\
\text { treated at home. }\end{array}$ \\
\hline
\end{tabular}

\section{Ramacciotti 2004}

\begin{tabular}{|c|c|}
\hline Methods & $\begin{array}{l}\text { Study design: randomised, open-label, multi-centre clinical trial } \\
\text { Exclusions post randomisation: not stated } \\
\text { Losses to follow-up: } 53.6 \% \text { at } 6 \text {-month follow-up } \\
\text { Intention-to-treat analysis: not indicated but analysis included all randomised participants }\end{array}$ \\
\hline Participants & $\begin{array}{l}\text { Country: Brazil } \\
\text { Setting: home or hospital } \\
\text { N: } 201 \text { randomised (104 enoxaparin, } 97 \text { UFH) } \\
\text { Age (years): mean } 64 \text { for home, } 44 \text { for hospitals } \\
\text { Sex: } 69 \text { male, } 132 \text { female } \\
\text { Inclusion criteria: age greater than or equal to } 18 \text { years, weight greater than or equal to } 50 \text { kg and < } 110 \\
\text { kg, DVT symptoms for } 10 \text { days or longer, proximal lower limb DVT (confirmed by duplex ultrasound or } \\
\text { venography), ready access to local health service, capable of using enoxaparin at home } \\
\text { Exclusion criteria: history of HIT or allergy to heparin; haemorrhagic diathesis; surgery within } 7 \text { days; } \\
\text { symptoms of PE, bilateral DVT; survival prognosis < } 6 \text { months; hepatic or renal failure; received ther- } \\
\text { apeutic doses of UFH or LMWH for } 24 \text { hours or longer in the previous } 48 \text { hours; in hospital for another }\end{array}$ \\
\hline
\end{tabular}


Ramacciotti 2004 (Continued)

reason, with stay anticipated to last $>3$ days; initial platelet count $<100,000 / \mathrm{mL}$; uncontrolled hypertension, with DBP greater than or equal to 180 ; initial APTT > 1.3 times the normal value; INR $>1.5$ at enrolment; indication for thrombolysis or venous thrombectomy

Interventions Treatment: once-daily sc injection of LMWH enoxaparin at a dose of $1.5 \mathrm{mg} / \mathrm{kg}$ for 5 to 10 days, given at home or in hospital at the discretion of the healthcare provider

Control: iv bolus injection of $5000 \mathrm{IU}$ of UFH followed by iv $500 \mathrm{IU} / \mathrm{kg} / \mathrm{d}$ adjusted to maintain an APTT of 1.5 to 2.5 times the normal value for 5 to 10 days in hospital

Anticoagulant: All participants received warfarin (with a targeted INR 2 to 3 ) for at least 3 months, starting at day 1 or 2 of treatment.

\begin{tabular}{ll}
\hline Outcomes & Primary: recurrent DVT, PE \\
& Secondary: major and minor bleeding \\
& Duration of follow-up: 6 months
\end{tabular}

Notes

\section{Risk of bias}

\begin{tabular}{lll}
\hline Bias & Authors' judgement & Support for judgement \\
\hline $\begin{array}{l}\text { Random sequence genera- } \\
\text { tion (selection bias) }\end{array}$ & Unclear risk & $\begin{array}{l}\text { Randomisation was by block 1:1 at each centre to ensure balance in each } \\
\text { treatment arm, but method of random sequence generation was not reported. }\end{array}$ \\
\hline $\begin{array}{l}\text { Allocation concealment } \\
\text { (selection bias) }\end{array}$ & High risk & $\begin{array}{l}\text { Each investigator received the randomisation scheme specifying the treat- } \\
\text { ment allocation for each participant enrolled in the study. Thus the investiga- } \\
\text { tor could foresee assignments and introduce selection bias. }\end{array}$ \\
\hline $\begin{array}{l}\text { Blinding of participants } \\
\text { and personnel (perfor- } \\
\begin{array}{l}\text { mance bias) } \\
\text { All outcomes }\end{array}\end{array}$ & High risk & Open-label \\
\hline
\end{tabular}

Blinding of outcome as- High risk Not reported

sessment (detection bias)

All outcomes

\begin{tabular}{lll}
\hline $\begin{array}{l}\text { Incomplete outcome data } \\
\text { (attrition bias) } \\
\text { All outcomes }\end{array}$ & High risk & $\begin{array}{l}\text { Only } 32.7 \% \text { of enoxaparin and } 46.4 \% \text { UFH participants were followed up after } \\
6 \text { months. }\end{array}$ \\
\hline $\begin{array}{l}\text { Selective reporting (re- } \\
\text { porting bias) }\end{array}$ & Low risk & All prespecified safety endpoints were reported. \\
\hline Other bias & Unclear risk & $\begin{array}{l}\text { Information was insufficient to determine whether other potential bias exists; } \\
\text { only } 36 \% \text { of participants randomised to treatment with enoxaparin were actu- } \\
\text { ally treated at home. }\end{array}$ \\
\hline
\end{tabular}

APTT: activated partial thromboplastin time.

DBP; diastolic blood pressure.

DVT: deep vein thrombosis.

HIT: heparin-induced thrombocytopenia.

INR: international normalised ratio.

IU: international units.

iv: intravenous.

LMWH: low molecular weight heparin. 
PE: pulmonary embolism.

PTS: post-thrombotic syndrome.

PTT: partial thromboplastin time.

sc: subcutaneous.

UFH: unfractionated heparin.

VKA: vitamin $\mathrm{K}$ antagonist.

VTE: venous thromboembolism.

Characteristics of excluded studies [ordered by study ID]

\begin{tabular}{|c|c|}
\hline Study & Reason for exclusion \\
\hline Aujesky 2011 & $\begin{array}{l}\text { Assessed effectiveness, safety, and efficacy of outpatient vs inpatient care for patients with acute } \\
\text { PE - not DVT }\end{array}$ \\
\hline Belcaro 1999 & $\begin{array}{l}\text { Participants were randomised to different forms of heparin rather than to home or hospital treat- } \\
\text { ment. }\end{array}$ \\
\hline Blattler 1998 & $\begin{array}{l}\text { Although this study is published as an RCT, the method described in the study report does not meet } \\
\text { the criteria for an RCT. }\end{array}$ \\
\hline Buller 2004 & Compared once-daily LMWH vs twice-daily doses in the outpatient setting - not hospital vs home \\
\hline Conner 1999 & Uncontrolled trial \\
\hline Fitzmaurice 2000 & This study was concerned with monitoring of oral anticoagulation at home or in the GP surgery. \\
\hline Frank 1998 & $\begin{array}{l}\text { Although this study is published as an RCT, the method described in the study report does not meet } \\
\text { the criteria for an RCT. }\end{array}$ \\
\hline Goldhaber 1998 & $\begin{array}{l}\text { Participants randomised to home care with LMWH were first required to be treated in hospital be- } \\
\text { fore being discharged. }\end{array}$ \\
\hline Grau 1998 & Not a randomised trial \\
\hline Grau 2001 & Retrospective study \\
\hline Green 1998 & Uncontrolled trial \\
\hline Hull 2000 & Trial concerned with prophylactic regimens using LMWH in patients undergoing hip arthroplasty \\
\hline Hull 2002 & Trial concerned with evaluating 2 long-term LMWH treatment protocols \\
\hline Hull 2009 & $\begin{array}{l}\text { Not home vs in-patient care; both groups of participants treated outside hospital. Usual care was } \\
\text { defined as tinzaparin for } 5 \text { days or longer, followed by warfarin for } 12 \text { weeks. }\end{array}$ \\
\hline Lindmarker 1996 & Uncontrolled trial \\
\hline Miles 1998 & Uncontrolled trial \\
\hline Modesto-Alapont 2006 & $\begin{array}{l}\text { Investigated the use of LMWH administered at home for prevention of VTE in patients with severe } \\
\text { chronic obstructive pulmonary disease }\end{array}$ \\
\hline O'Shaugnessy 1998 & Uncontrolled trial \\
\hline Otero 2010 & Focussed on PE - not DVT \\
\hline
\end{tabular}




\begin{tabular}{ll}
\hline Study & Reason for exclusion \\
\hline Pineo 2003 & Trial concerned with evaluating 2 long-term LMWH treatment protocols \\
\hline Rymes 2002 & Retrospective study \\
\hline Ting 1998 & Uncontrolled trial \\
\hline Wells 1998 & Controlled trial of nurse vs patient injection. Not related to admission or home treatment \\
\hline White 1989 & This trial was concerned with monitoring of oral anticoagulation at home or in the GP surgery. \\
\hline Wilson 2003 & $\begin{array}{l}\text { Study design not home vs in-patient, anticoagulant clinics vs family physician clinic. Intervention } \\
\text { was oral anticoagulant - not LMWH. Study population included anyone who required warfarin for at } \\
\text { least } 3 \text { months - not specifically for DVT. }\end{array}$ \\
\hline Wimperis 1998 & Uncontrolled trial \\
\hline
\end{tabular}

DVT: deep vein thrombosis.

LMWH: low molecular weight heparin.

PE: pulmonary embolism.

RCT: randomised controlled trial.

VTE: venous thromboembolism.

\section{DATA AND ANALYSES}

\section{Comparison 1. Treatment of DVT at home versus treatment in hospital}

\begin{tabular}{lllll}
\hline $\begin{array}{l}\text { Outcome or subgroup } \\
\text { title }\end{array}$ & No. of studies & $\begin{array}{l}\text { No. of partici- } \\
\text { pants }\end{array}$ & Statistical method & Effect size \\
\hline 1 Recurrence of VTE & 6 & 1708 & Risk Ratio (M-H, Fixed, 95\% Cl) & $0.58[0.39,0.86]$ \\
\hline 2 Major bleeding & 6 & 1708 & Risk Ratio (M-H, Fixed, 95\% Cl) & $0.67[0.33,1.36]$ \\
\hline 3 Minor bleeding & 6 & 1708 & Risk Ratio (M-H, Fixed, 95\% Cl) & $1.29[0.94,1.78]$ \\
\hline 4 Death & 6 & 1708 & Risk Ratio (M-H, Fixed, 95\% Cl) & $0.69[0.44,1.09]$ \\
\hline
\end{tabular}

Analysis 1.1. Comparison 1 Treatment of DVT at home versus treatment in hospital, Outcome 1 Recurrence of VTE.

\begin{tabular}{|c|c|c|c|c|c|}
\hline \multirow[t]{2}{*}{ Study or subgroup } & $\begin{array}{c}\text { Treatment } \\
\text { (Home) }\end{array}$ & $\begin{array}{l}\text { Control } \\
\text { (Hospital) }\end{array}$ & Risk Ratio & Weight & Risk Ratio \\
\hline & $n / N$ & $n / N$ & M-H, Fixed, 95\% Cl & & Fixed, $95 \% \mathrm{Cl}$ \\
\hline Boccalon 2000 & $1 / 99$ & $2 / 102$ & 1 & $3.11 \%$ & $0.52[0.05,5.59]$ \\
\hline Chong 2005 & $4 / 150$ & $14 / 148$ & 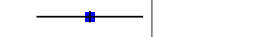 & $22.24 \%$ & $0.28[0.09,0.84]$ \\
\hline Daskalopoulos 2005 & $3 / 55$ & $6 / 53$ & $\longrightarrow$ & $9.64 \%$ & $0.48[0.13,1.83]$ \\
\hline Koopman 1996 & $14 / 202$ & $17 / 198$ & $\rightarrow$ & $27.09 \%$ & $0.81[0.41,1.59]$ \\
\hline Levine 1996 & $13 / 247$ & $17 / 253$ & $\longrightarrow$ & $26.5 \%$ & $0.78[0.39,1.58]$ \\
\hline Ramacciotti 2004 & $2 / 104$ & $7 / 97$ & $\longrightarrow$ & $11.43 \%$ & $0.27[0.06,1.25]$ \\
\hline
\end{tabular}




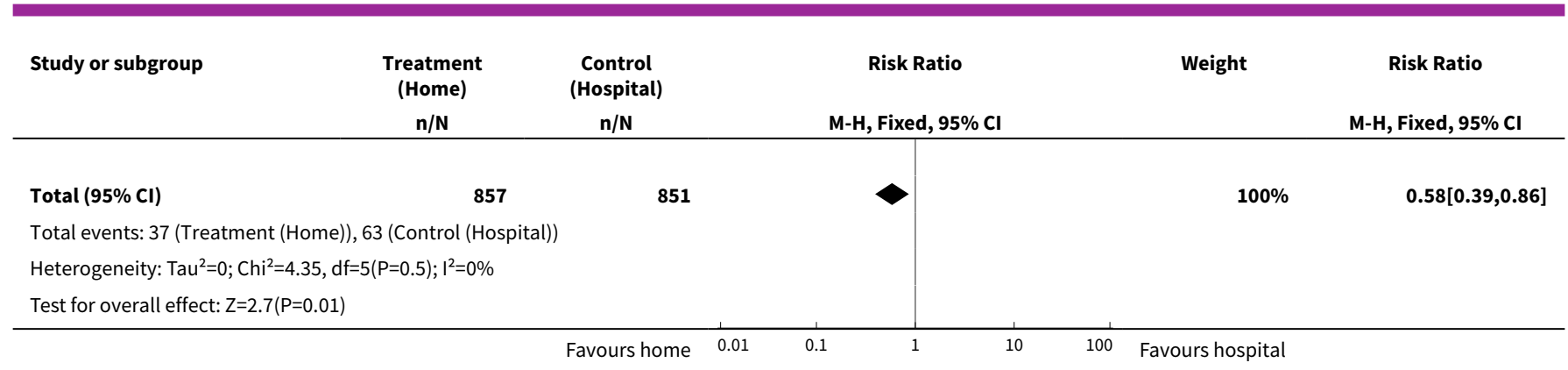

\section{Analysis 1.2. Comparison 1 Treatment of DVT at home versus treatment in hospital, Outcome 2 Major bleeding.}

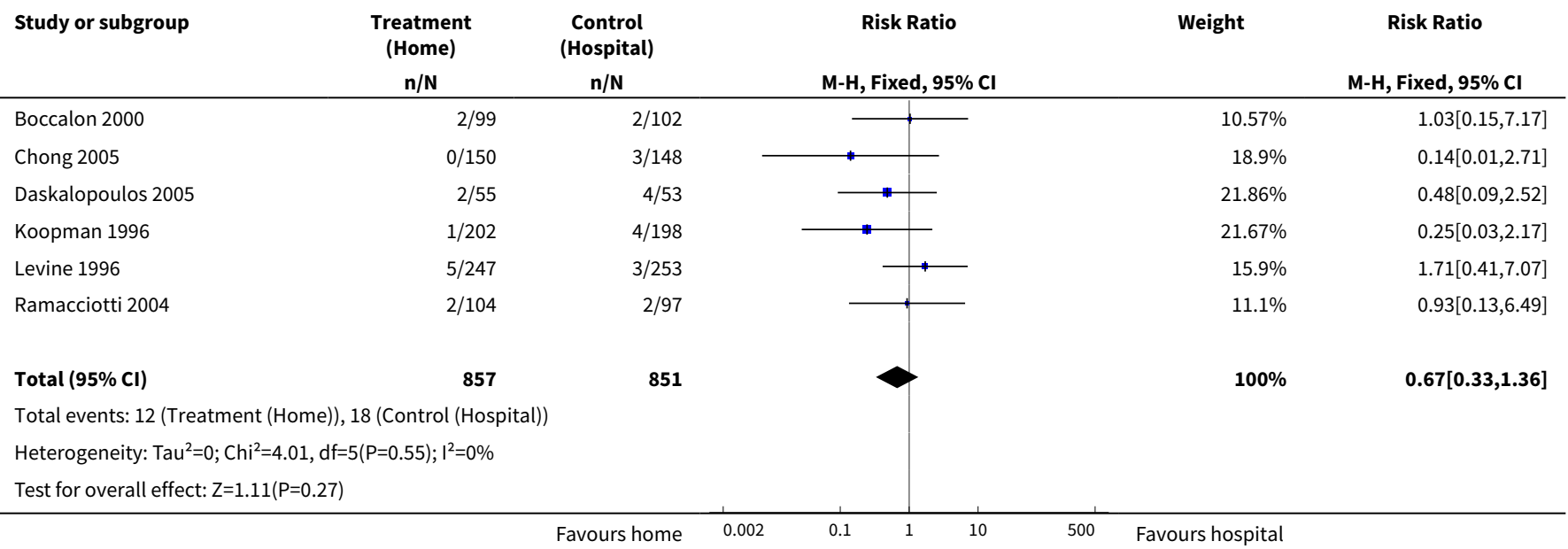

Analysis 1.3. Comparison 1 Treatment of DVT at home versus treatment in hospital, Outcome 3 Minor bleeding.

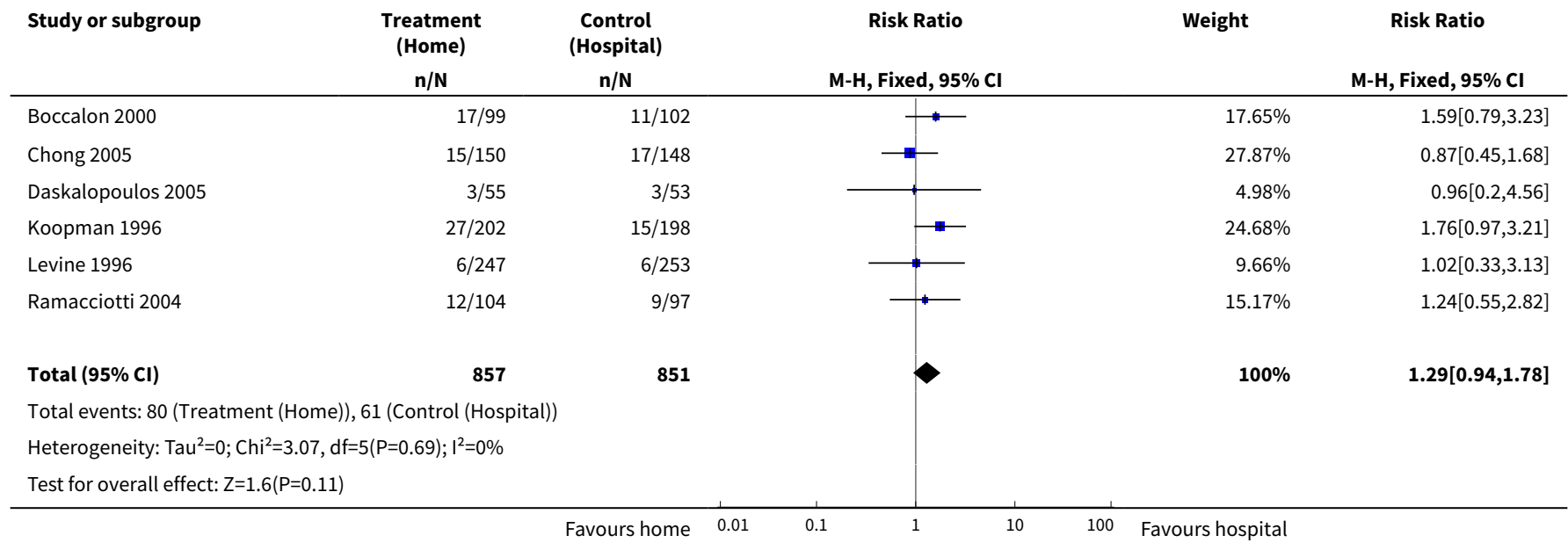


Analysis 1.4. Comparison 1 Treatment of DVT at home versus treatment in hospital, Outcome 4 Death.

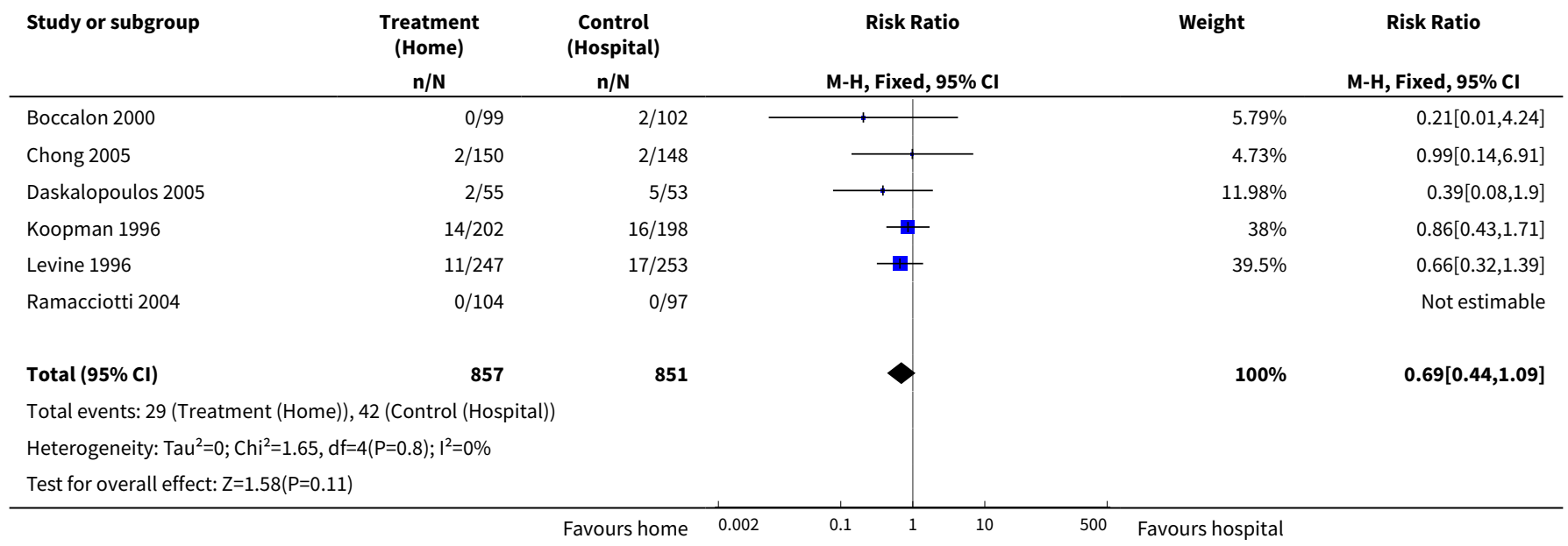




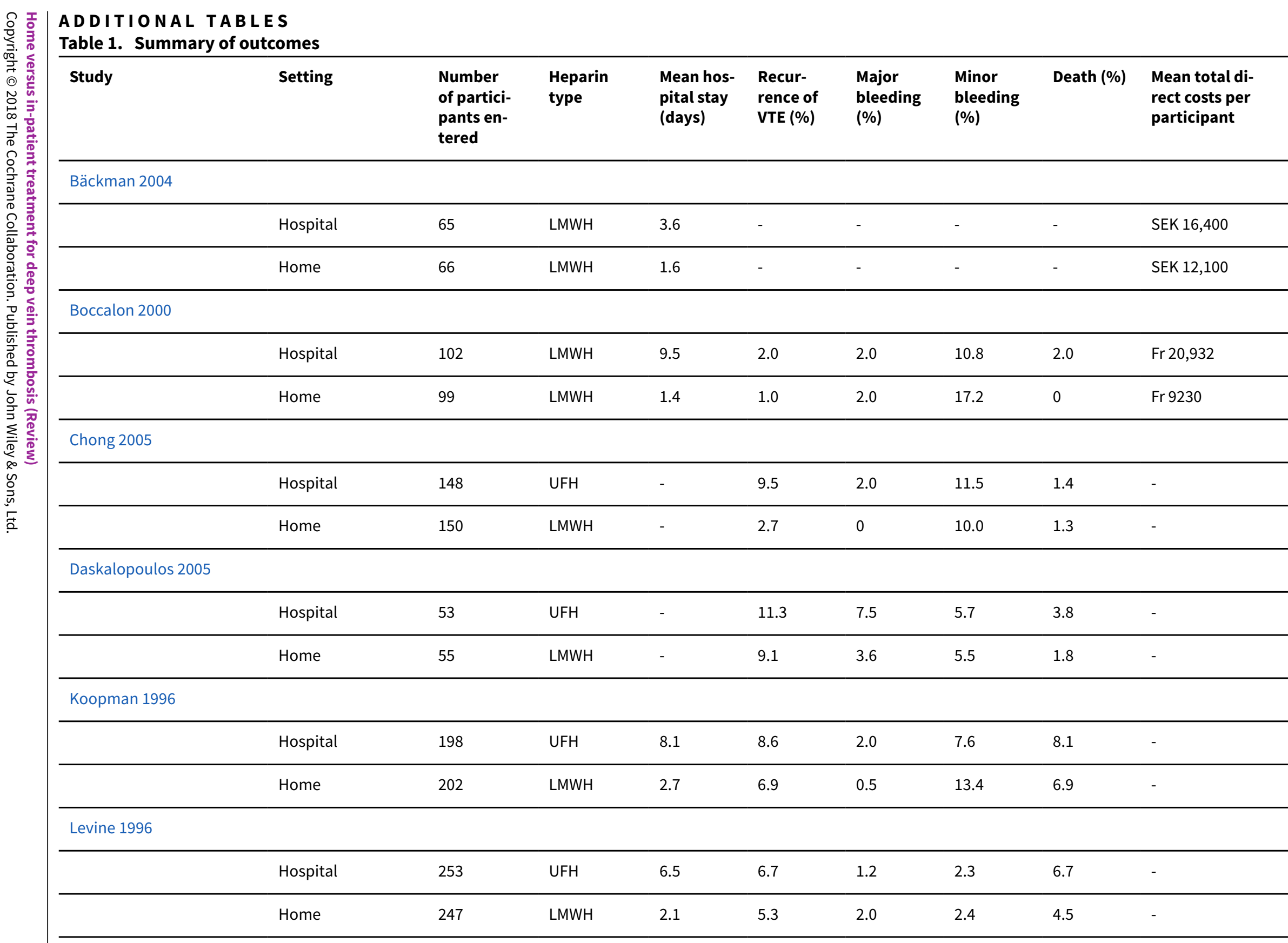


Table 1. Summary of outcomes (Continued)

Ramacciotti 2004

\begin{tabular}{llllllllll}
\hline Hospital & 97 & LMWH & 3 & 2 & 2 & 12 & - \\
\hline Home & 104 & UFH & 7 & 7 & 3 & 9 & - \\
\hline
\end{tabular}

LMWH: low molecular weight heparin.

UFH: unfractionated heparin.

VTE: venous thromboembolism

\section{Table 2. Percentage of participants treated at home}

\begin{tabular}{|c|c|c|c|c|c|c|c|}
\hline Participants & $\begin{array}{l}\text { Bäckman } \\
2004\end{array}$ & $\begin{array}{l}\text { Boccalon } \\
2000\end{array}$ & Chong 2005 & $\begin{array}{l}\text { Daskalopou- } \\
\text { los } 2005\end{array}$ & $\begin{array}{l}\text { Koopman } \\
1996\end{array}$ & Levine 1996 & $\begin{array}{l}\text { Ramacciotti } \\
2004\end{array}$ \\
\hline Randomised (N) & 131 & 201 & 298 & 108 & 400 & 500 & 201 \\
\hline Excluded after randomisation (\%) & 5.3 & 18.9 & 20 & 5.5 & 0 & 0 & 0 \\
\hline $\begin{array}{l}\text { Randomised to home/LMWH treatment and were } \\
\text { actually treated at home (not hospitalised) (\%) }\end{array}$ & $40^{a}$ & 74 & $23 b$ & $100^{c}$ & 36 & 48.5 & 36 \\
\hline
\end{tabular}

a Bäckman 2004 reported that 40\% of those randomised to home treatment remained at home, and 40\% were hospitalised; it is unclear what happened with the remaining $20 \%$; 36 randomised participants changed treatment, 26 of whom changed from hospital to home, and 10 from home to hospital.

$b_{C}$ Chong 2005 reported that $23 \%$ of those randomised to home treatment were exclusively treated at home, $12 \%$ were hospitalised and discharged within a day, and $35 \%$ were hospitalised for one night, $23 \%$ for two nights, and $8 \%$ for three or more nights.

cDaskalopoulos 2005 initially reported: "Patients allocated to receive treatment with LMWH underwent no hospitalizations at all", but later in the text trial authors state: "The number of major events requiring hospitalization was significantly lower in the LMWH group", making it unclear whether those randomised to LMWH were exclusively treated at home.

LMWH: low molecular weight heparin. 
Table 3. Uncontrolled trials - participant demographics

\begin{tabular}{|c|c|c|c|}
\hline Trial author & Referrals & Positive scans & $\%$ home treated \\
\hline Grau 1998 & - & 71 & 55.0 \\
\hline Green 1998 & 373 & 119 & 37.5 \\
\hline Lindmarker 1996 & - & $434 a$ & 100.0 \\
\hline Miles 1998 & - & 966 & 90.0 \\
\hline O'Shaugnessy 1998 & 1093 & 160 & 99.9 \\
\hline Ting 1998 & - & $53^{b}$ & 100.0 \\
\hline Wimperis 1998 & 447 & 134 & 80.0 \\
\hline Total & & 1451 & \\
\hline
\end{tabular}

$a_{3}$ days' hospital treatment before discharge.

bexcluding distal thrombosis.

\section{APPENDICES}

\section{Appendix 1. CENTRAL search strategy}

\begin{tabular}{|c|c|c|}
\hline \#1 & MESH DESCRIPTOR Thrombosis & 1261 \\
\hline \#2 & MESH DESCRIPTOR Thromboembolism & 919 \\
\hline \#3 & MESH DESCRIPTOR Venous Thromboembolism & 257 \\
\hline \#4 & MESH DESCRIPTOR Venous Thrombosis EXPLODE ALL TREES & 2036 \\
\hline \#5 & $\begin{array}{l}\text { (thrombus* or thrombopro* or thrombotic* or thrombolic }{ }^{\star} \text { or thromboem- } \\
\text { boli* or thrombos }^{\star} \text { or embol*):TI,AB,KY }\end{array}$ & 18960 \\
\hline \#6 & MESH DESCRIPTOR Pulmonary Embolism EXPLODE ALL TREES & 746 \\
\hline \#7 & (PE or DVT or VTE):TI,AB,KY & 4979 \\
\hline \#8 & ((vein* or ven*) near thromb*):TI,AB,KY & 6702 \\
\hline \#9 & (blood near3 clot $^{\star}$ ):TI,AB,KY & 2963 \\
\hline \#10 & (pulmonary near3 $\left.\operatorname{clot}^{\star}\right): \mathrm{TI}, \mathrm{AB}, \mathrm{KY}$ & 5 \\
\hline \#11 & (lung near3 clot $\left.^{\star}\right): T I, A B, K Y$ & 4 \\
\hline \#12 & \#1 OR \#2 OR \#3 OR \#4 OR \#5 OR \#6 OR \#7 OR \#8 OR \#9 OR \#10 OR \#11 & 24595 \\
\hline \#13 & MESH DESCRIPTOR Outpatients & 983 \\
\hline
\end{tabular}

Home versus in-patient treatment for deep vein thrombosis (Review) 
(Continued)

\begin{tabular}{|c|c|c|}
\hline$\# 14$ & MESH DESCRIPTOR Inpatients & 703 \\
\hline \#15 & MESH DESCRIPTOR Patient Care EXPLODE ALL TREES & 48022 \\
\hline \#16 & MESH DESCRIPTOR Ambulatory Care & 2843 \\
\hline$\# 17$ & MESH DESCRIPTOR Home Nursing & 253 \\
\hline \#18 & MESH DESCRIPTOR Hospitalization EXPLODE ALL TREES & 10891 \\
\hline \#19 & MESH DESCRIPTOR Outpatient Clinics, Hospital & 541 \\
\hline \#20 & in-patient:TI,AB,KY & 4947 \\
\hline \#21 & inpatient:TI,AB,KY & 5166 \\
\hline \#22 & hospitali*:TI,AB,KY & 25539 \\
\hline \#23 & bed-ridden:TI,AB,KY & 20 \\
\hline \#24 & bedridden:TI,AB,KY & 107 \\
\hline \#25 & home:TI,AB,KY & 19783 \\
\hline \#26 & out-patient:TI,AB,KY & 1246 \\
\hline$\# 27$ & outpatient:TI,AB,KY & 15589 \\
\hline \#28 & ambulatory $^{\star}: \mathrm{TI}, \mathrm{AB}, \mathrm{KY}$ & 14873 \\
\hline \#29 & domicil $^{\star}: T I, A B, K Y$ & 383 \\
\hline \#30 & $\begin{array}{l}\# 13 \text { OR \#14 OR \#15 OR \#16 OR \#17 OR \#18 OR \#19 OR \#20 OR \#21 OR \#22 OR \#23 } \\
\text { OR \#24 OR \#25 OR \#26 OR \#27 OR \#28 OR \#29 }\end{array}$ & 108891 \\
\hline \#31 & \#12 AND \#30 & 3043 \\
\hline
\end{tabular}

\section{Appendix 2. Trials registries searches}

Clinicaltrials.gov

44 studies found for: embolism AND home

WHO

809 records for 256 trials for: embolism AND home

ISRCTN

18 records for: embolism AND home

\section{FEE DBACK}

\section{Anticoagulant feedback, 14 February 2011}

\section{Summary}

Feedback received on this review, and other reviews and protocols on anticoagulants, is available on the Cochrane Editorial Unit website at http://www.editorial-unit.cochrane.org/anticoagulants-feedback. 
WHAT'S NEW

\begin{tabular}{lll}
\hline Date & Event & Description \\
\hline 29 May 2017 & New search has been performed & $\begin{array}{l}\text { Searches rerun. One new study included and five new studies ex- } \\
\text { cluded }\end{array}$ \\
\hline 29 May 2017 & $\begin{array}{l}\text { New citation required but conclusions } \\
\text { have not changed }\end{array}$ & $\begin{array}{l}\text { Searches rerun. One new study included and five new studies ex- } \\
\text { cluded. Review text updated to incorporate updated Cochrane } \\
\text { requirements. New headings added, included studies assessed } \\
\text { for risk of bias, GRADE ratings generated, and 'Summary of find- } \\
\text { ings' table populated. Conclusions not changed }\end{array}$ \\
\hline
\end{tabular}

\section{H I S T O R Y}

Protocol first published: Issue 2, 2000

Review first published: Issue 2, 2001

\begin{tabular}{lll}
\hline Date & Event & Description \\
\hline 14 February 2011 & Amended & Link to anticoagulant feedback added \\
\hline 13 May 2008 & Amended & Converted to new review format \\
\hline 9 November 2007 & New search has been performed & $\begin{array}{l}\text { No new trials found. One additional secondary reference added } \\
\text { to Ramacciotti 2004 (included study). Conclusions not changed }\end{array}$ \\
\hline 22 May 2007 & $\begin{array}{l}\text { New citation required but conclusions } \\
\text { have not changed }\end{array}$ & $\begin{array}{l}\text { New team of review authors. Two new included trials and six new } \\
\text { excluded trials. Overall conclusions strengthened with further } \\
\text { evidence }\end{array}$ \\
\hline 27 May 2004 & New search has been performed & No new trials found. Review updated as it stands \\
\hline
\end{tabular}

\section{CONTRIBUTIONS OF AUTHORS}

RO: independently selected articles; assessed studies for inclusion; assessed the methodological quality of selected trials; extracted data; and contributed to discussion of the final report of the review.

EO: independently selected articles, assessed studies for inclusion, and assessed the methodological quality of selected trials; extracted data; performed data entry and analysis and drafted the report; evaluated evidence for the review; and contributed to discussion of the final report of the review.

RF: performed data entry and analysis; drafted the report; evaluated evidence for the review; and contributed to discussion of the final report of the review.

\section{DECLARATIONSOF INTEREST}

RO: none known.

EO: none known.

RF: none known.

\section{SOURCES OF SUPPORT}

\section{Internal sources}

- No sources of support supplied 


\section{External sources}

- Chief Scientist Office, Scottish Government Health Directorates, The Scottish Government, UK.

The Cochrane Vascular editorial base is supported by the Chief Scientist Office.

- National Institute of Health Research (NIHR), UK.

This project was supported by the NIHR, via Cochrane Programme Grant funding to Cochrane Vascular (10/4001/14). The views and opinions expressed therein are those of the review authors and do not necessarily reflect those of the Systematic Reviews Programme, NIHR, NHS, or the Department of Health.

\section{DIFFERENCES BETWEEN PROTOCOLANDREVIEW}

We assessed the methodological quality of included studies by using Cochrane's 'Risk of bias' tool presented in Higgins 2011 instead of the method previously used for Jadad 1996. We added a 'Summary of findings' table and assessed the quality of evidence according to the GRADE method (Atkins 2004).

We broadened the secondary outcome of patient satisfaction to include quality of life, as this outcome is more commonly used and is well accepted.

We renamed outcomes 'PE' and 'recurrent DVT' as 'recurrence of VTE'.

\section{INDEX TERMS}

\section{Medical Subject Headings (MeSH)}

*Home Care Services; *Hospitalization; Cost-Benefit Analysis; Fibrinolytic Agents [*therapeutic use]; Hemorrhage [chemically induced]; Heparin [adverse effects] [*therapeutic use]; Heparin, Low-Molecular-Weight [adverse effects] [therapeutic use]; Randomized Controlled Trials as Topic; Recurrence; Secondary Prevention; Thrombolytic Therapy [standards]; Venous Thrombosis [*drug therapy] [mortality]

\section{MeSH check words}

Humans 